Hispania Sacra, LX

121, enero-junio 2008, 231-266, ISSN: 0018-215-X

\title{
LES MADRILÈNES FACE À LA VIOLENCE: LA PRATIQUE DU PARDON PRIVÉ AU XVIIE SIÈCLE
}

\author{
POR \\ OLIVIER CAPOROSSI \\ (EHEHI-Casa de Velázquez)
}

\begin{abstract}
RESUMEN
Este trabajo propone estudiar los apartamientos de los madrileños del siglo XVII, y conservados en los perdones reales del Viernes Sancto o en las declaraciones de los heridos del Hospital General de la villa, no sólo como actas judiciales sino más bien como unos discursos religiosos, fundadores de una exorcización de la violencia individual y determinados por numerosos modelos religiosos. Se demuestra la capacidad de estos modelos discursivos e ideológicos para promover la concordia, ejercer una censura sobre el discurso del apartamiento e influir sobre los propios modelos jurídicos.
\end{abstract}

Palabras ClaVE: Apartamiento, Homicidio, Madrid, Siglo XVII, Perdón, Religión.

\section{ABSTRACT}

This work offers to study the apartamientos established by the Madrilenians in the 17th century and kept in the pardons of Good Friday or in the statements of injured people in the general hospital of the town. They are studied not only as legal transactions but, above all, as religious speeches at the origin of an exorcising of individual violence and as determined by many religious models after the origin of an exorcising of individual violence ans as determined by many religious models were able to promote peace, to create censorship on the contents of the apartamientos and influence even the legals models.

KEY WORDS: Apartamiento, Murder, Madrid, 17th century, Forgiveness, Catholic religious.

Recibido/Received 15-02-2007

Aceptado/Accepted 15-04-2007 
INTRODUCTION: L'ESPACE SOCIAL ET DISCURSIF DE L'APARTAMIENTO

L'anthropologie historique des conflits a mis en avant la dialectique du punir et du pardonner en inscrivant la rémission et le pardon dans l'évolution de la régulation sociale depuis le Moyen-Âge ${ }^{1}$. La pratique du pardon privé dans une société très attachée aux valeurs de l'honneur et de la réputation, est l'un des modes de résolution des conflits qui semble plus qu'aucun autre privilégier la paix, car elle aurait la capacité d'arrêter le processus de la vengeance. L'apartamiento en représente la forme notariale et suffit parfois à endiguer la montée de la violence ou à éviter un procès long et coûteux. Mais les rares études de cette procédure infrajudiciaire ne permettent pas encore d'en mesurer toute la portée ${ }^{2}$. Mais, plus que les sources notariales, ce sont les archives de la cour qui nous intéressent ici, car elles nous permettent de comprendre l'intégration de l'apartamiento dans l'économie de la grâce royale 3 .

Le pardon de la partie offensée, observé à partir des procès de pardons du Vendredi Saint et d'autres pardons royaux accordés par Philippe IV à ses vassaux madrilènes, est le fruit d'une longue négociation entre les familles en litige, qui peut commencer dès la mise en place d'une procédure pénale par les instances judiciaires de la cour et de la ville de Madrid ${ }^{4}$. Le fonds des pardons du Vendredi Saint, dont la gestion appartient depuis 1644 au conseil de la Chambre de Castille (Camara de Castilla) ${ }^{5}$, est largement dominé par des affaires d'homicides ${ }^{6}$. Le rôle du rapporteur du conseil de la Chambre de Castille est déterminant puisque c'est à partir de son résumé de la cause pénale que les conseillers choisissent ceux qui méritent la considération du monarque et proposent une liste de noms à ce dernier ${ }^{7}$. A l'avènement de Philippe IV, la Camara

\footnotetext{
${ }^{1}$ Claude GAUVARD, «Conclusion», Le règlement des conflits au Moyen Âge. XXIe congrès de la SHMESP, Paris, Publications de la Sorbonne, 2001, p. 369-391.

2 Tomás A. MANTECON, «Criminals and royal pardon in the 18 th century Spain», Jacqueline HoAReAu Dodineau, Xavier Rousseaux et Pascal TeXIER (textes réunis par), Le Pardon. Cahiers de l'Institut d'Anthropologie Juridique n`3, Limoges, 1999, p. 485-493. Angel APONTE MARIN, «Apuntes sobre la delincuencia en Jaen en la primera mitad del siglo XVII», Chronica Nova, n¹5, 1986-1987, p. 9-16.

${ }^{3}$ Elisabeth BaLANCY, «Le pouvoir du pardon. Famille-État dans l'Espagne du XVIIe siècle», Michel BERTRAND (ed.), Pouvoirs de famille, familles de pouvoir, Toulouse, Université de Toulouse Le Mirail, 2005, p. 457-477.

${ }^{4}$ Voir les chapitres correspondants dans notre travail, O. CAPOROSSI, Les justices royales et la criminalité madrilène sous le règne de Philippe IV (1621-1665). Unité et multiplicité de la juridiction royale à la cour d'Espagne. Thèse de doctorat d'histoire moderne soutenue le 20/12/2002 à l'université de Toulouse Le Mirail.

${ }^{5}$ Ma I. RodríGueZflores, El perdon real en Castilla (Siglos XIII-XVIII), Salamanca, 1971, p. 154.

${ }^{6}$ Elles représentent 97 \% des demandes de grâce. Rudy CHAULET, «La violence en Castille au XVIIIe siècleà travers les Indultos de Viernes Santo (1623-1699)», Crime, Histoire et Sociétés, $n^{\circ} 2$, (1997), 5-28.

7 Manuel Amador González Fuertes, La organización Institucional de la Cámara de Castilla en la Época Borbonica, Córdoba, 2002, p. 145.
}

Hispania Sacra, LX

121, enero-junio 2008, 231-266, ISSN: 0018-215-X 
de Castilla est formée par le président de Castille, quatre conseillers royaux et trois secrétaires, sans oublier deux rapporteurs. Les affaires sont traitées par les secrétaires de la Chambre de Castille. Le secrétaire de la «Camara y Estado de Castilla» s'occupe, avec l'aide du rapporteur correspondant, des «las mercedes y gracias que su Magestad concede, perdones de muertes, delitos» ${ }^{8}$.

La grâce royale en matière pénale est multiple. A l'ouverture des Cortès, les députés supplient le roi catholique de prononcer un pardon général des peines d'amendes et des peines personnelles. Seules les condamnations pour plantations de vignes et les peines prononcées par les juges de résidence sont exclues de cette clémence royale qui est traditionnellement proclamée avant les nouvelles lois négociées avec les cortès. Le pardon du roi se manifeste aussi lors d'une entrée royale à l'occasion du retour de la cour d'un voyage d'importance, de l'accueil de la reine à Madrid, de la naissance d'un infant comme celle de Baltasar Carlos en $1629^{9}$, du mariage du roi comme celui de Philippe IV avec Marianne d'Autriche en $1649^{10}$, de la réception d'un prince comme ce fut le cas pour le prince de Galles Charles venu négocier en 1623 son mariage avec une infante espagnole. La célébration d'une victoire militaire, comme celle de Fuenterabie contre les Français (1639) donne souvent lieu à un pardon général. Il en est de même à l'occasion des fêtes de la Nativité et de Pâques: ce sont les pardons du Vendredi Saint. Lors d'une cérémonie solennelle dans la chapelle royale, le monarque pose sa main sur les mémoires et les causes des délinquants sélectionnés par le conseil de la Chambre de Castille que lui proposent deux chapelains d'honneur sur deux plats. Il prononce ensuite les paroles rituelles: «Yo os perdono, porque Dios me perdone». Selon le juriste Juan López de Cuellar y Vega, ce sont ces «palabras que asseguran la protección Divina, contra los enemigos de su Corona» ${ }^{11}$. Le Christ s'incarne ainsi métaphoriquement dans le geste du monarque qui, plus que jamais, mérite ici son titre de roi catholique, et exprime aux initiés -c'est-à-dire aux courtisans réunis dans la chapelle royale- la nature sacrée de la monarchie de droit divin. La cérémonie du pardon royal célèbre le mystère de la monarchie catholique.

Les Madrilènes représentent une part importante des justiciables bénéficiaires de cette grâce du souverain. Les derniers Habsbourg entretiennent, en effet, une relation privilégiée avec la ville de cour depuis $1606^{12}$. Les alcades de cour

${ }^{8}$ G. GonZÁlez Davila, Teatro de las grandezas de la villa de Madrid corte de los reyes, Madrid, 1623 , p. 406.

${ }^{9}$ AHN, Consejos, libro 1214, f. 416-421.

10 AHN, Consejos, libro 1234, f. 208-209.

11 J. López de Cuellar y Vega, Tratado politico juridico. Practica de indultos, Pamplona, 1690, p. 41.

12 Olivier CAPOROSSI, «Restaurer la cour à Madrid (1606-1621) une nouvelle police pour la Babylone du Crime?», Mélanges de l'École Française de Rome Italie et Méditerranée (MEFRIM), t. 115, 2003, 2, 751-776. 
comme le corrégidor sont les principaux acteurs judiciaires de ces procès pénaux. Les alcades de cour constituent la cinquième chambre du conseil de Castille, c'est-à-dire un tribunal supérieur dont la juridiction civile et pénale s'étend à la cour et aux cinq lieues à l'entour. Le corrégidor de Madrid, dont la juridiction comprend la ville de Madrid et tous les territoires urbains et ruraux de son corregimiento, est un officier de justice placé sous la tutelle du conseil de Castille, comme les alcades de cour. Mais ses condamnations sont susceptibles d'appel devant les alcades de cour. D'autres autorités judiciaires apparaissent dans les causes pénales des délinquants qui sollicitent le pardon individuel du roi catholique. C'est le cas, par exemple, des capitaines de chaque garde royale (les Archers, la compagnie Allemande ou encore la garde Espagnole) qui ont une juridiction de première instance en matière pénale sur leurs soldats. En deuxième instance, les valets de maison du roi sont jugés par la junte royale du Bureau que préside le grand-maître, mayordomo mayor.

La définition de l'apartamiento semble d'abord juridique. Dans un traité de pratique judiciaire édité en 1690, le licencié Juan López de Cuellar y Vega, avocat des conseils royaux, considère que l'obtention du pardon de la partie offensée reste la condition première pour espérer recevoir l'indulgence du Prince ${ }^{13}$. Le juriste reprend l'idée défendue par la théologie selon laquelle un particulier, fut-il le juge suprême de la communauté, ne peut pardonner les maux causés par un tiers à un autre tiers. En effet, le roi catholique n'a pas l'habitude de porter préjudice aux droits des victimes, même s'il demeure libre de le faire en droit lorsque le bien de la communauté en dépend. Cette pratique du pardon engage seulement l'accusé ou le condamné. Pour Domingo de Soto le monarque n'est pas le magistrat vengeur des intérêts d'un particulier car il n'agit pas de sa propre autorité. Il est le détenteur de l'autorité publique et à ce titre défend la société des offenses qui lui sont portées. Juan López de Cuellar y Vega constate par ailleurs que l'absence d'apartamiento rend caduque les effets de la grâce royale. Celle-ci, pour être pleinement efficace, doit être précédée de la fin réelle de la querelle.

Ecrire cela à la fin du XVIIe siècle, c'est aussi reconnaître que les mentalités judiciaires animées par l'idéologie de l'honneur, légitiment encore le recours à la violence privée pour éteindre une querelle dans le sang, quelle que soit la décision du roi ${ }^{14}$.

Mais la définition de l'apartamiento répond aussi aux impératifs de l'économie du salut, comme nous le montre la lecture des dernières déclarations de

13 J. López de Cuellar y Vega, Tratado juridico politico. Practica de indultos, p. 10-17.

${ }^{14}$ L'insulte motive bien des rixes et la vengeance d'honneur est fréquente au XVIIe siècle. B. BENNASSAR, L'Homme espagnol. Attitudes et mentalités du XVIe au XIXe siècle, Paris, reed. 1992 (1975), p. 182 .

Hispania Sacra, LX

121, enero-junio 2008, 231-266, ISSN: 0018-215-X 
blessés mourant à l'hôpital ou sur le lieu de leur agression. La pastorale catholique présente les rapports du pénitent et du prêtre dans le cadre de la confession, comme celui d'un accusé devant un tribunal ${ }^{15}$. Le tribunal de la pénitence est un modèle à l'œuvre dans les discours d'apartamiento .

Le discours et la pratique du pardon de la partie offensée oscillent donc souvent entre la valorisation juridique et l'économie du salut. Par exemple, l'aveu du délit par l'accusé n'implique pas seulement une possible application de la peine du tribunal mais la reconnaissance du péché qui, pour Luis de León caractérise tous ceux qui transgressent la loi du Prince ${ }^{16}$.

Les actes d'apartamiento interrogent la place du religieux dans la culture des conflits et les relations entre espace privé et espace public. Dans le Tractatus de Legibus ac Deo legislatore, Francisco Suárez intègre la notion de délit et celle de péché dans un ordre commun, celui des lois humaines parce qu'elles participent toutes les deux sans distinction au système hiérarchique de la Loi: loi éternelle, loi divine, loi naturelle, lois humaines ${ }^{17}$.

Les pardons privés manifestent des stratégies collectives qui relèvent de la dialectique entre l'offense privée et l'offense publique. La question de la réparation et ses implications morales est souvent affirmée par les théologiens. Pour Bartolomé Carranza, qui en 1540, se réfère à Thomas d'Aquin, Saint augustin, et à Saint Paul, le salut du délinquant-pécheur implique nécessairement la réparation ${ }^{18}$.

Cette dialectique prend une valeur d'exemplarité pour la monarchie catholique dans le contexte politique et social de la restauration d'une nouvelle cour d'Espagne à Madrid. Les stratégies d'exorcisme de l'apartamiento sont-elles capables de pacifier les rapports sociaux d'une métropole urbaine en pleine croissance? La ville de cour atteint les 127000 habitants dès 161719 , et en compte 150000 vers 1685 . La place du pardon privé dans la découverte espagnole du gigantisme urbain est aussi un moyen pour les Madrilènes de résister à l'appropriation de la négociation pacificatrice par les tribunaux du roi concurrents. Madrid compte, par exemple en 1663, plus d'une soixantaine de juridictions qui limitent l'exercice de la police par les auxiliaires des alcades de cour.

15 J. DelumEAu, Le péché et la peur. La culpabilisation en Occident XIIIe-XVIIIe siècles, Paris, Fayard, 1983, p. 520 .

16 Fray L. de LEÓn, De legibus, Madrid, CSIC, 1963 (1571), p. 102.

${ }^{17}$ La différenciation entre le péché et le délit n'apparaît qu'à la fin du XVIIe siècle chez certains auteurs comme Christian Thomasius. B. ClaVERo, «Delito y pecado. Noción y escala de transgresiones» F. TOMÁs Y VALIENTE et, Sexo barroco y otras transgresiones premodernas, Madrid, Alianza, 1990, p. 66-67.

18 Bartolomé. Carranza, De justitia et iure, Barañáin, EUNSA, 2003, p. 88.

19 V. Pinto Crespo y S. Madrazo Madrazo (dir.), Madrid Atlas historico de la ciudad siglos IX$X I X$, Madrid, 1995, p. 143. 
L'apartamiento produit ainsi la rencontre des trois figures majeures de la société espagnole d'Ancien Régime: le théologien et le moraliste, le juge et le juriste, le justiciable. Trois acteurs qui définissent trois discours et donc trois regards distincts qui, tous, cherchent à s'inscrire dans la stratégie globale de la grâce royale, de l'arbitrium suprême. La relecture de la philosophie thomiste par l'école de Salamanque produit au XVIe siècle un nouvel argumentaire pour endiguer la violence endémique de l'honneur. Le confesseur de Charles Quint (1516-1556), Domingo de Soto inaugure dans son De Iustitia et Iure une pensée du pardon individuel et montre que si chacun est maître de ses biens il l'est aussi de sa réputation et de son honneur. L'homme offensé est donc en droit d'y renoncer et d'obéir à la parole du Christ en recommandant aux siens comme à lui-même l'amour de ses ennemis ${ }^{20}$. La mémoire de la victime légitime ainsi la négociation entre la famille offensée et l'auteur de l'homicide. La rhétorique de la littérature des théologiens sur le droit et la justice, forme la charpente religieuse du discours de l'apartamiento des procès de pardons particuliers et des pardons du Vendredi Saint que nous avons étudiés pour les années 1620-1675. Les juristes ont reçu cet enseignement dans les universités espagnoles qui les ont formés et, à la lumière de leur expérience professionnelle de notaire, d'avocat, de juge délivrent à leurs confrères un modèle juridico-religieux de l'apartamiento dans les livres de pratique judiciaire (les practicas) dont les éditions se multiplient après 1567. Enfin, le récit de certaines chroniques judiciaires, comme celle du fourrier de la garde espagnole, Diego de Soto y Aguilar rédigée vers 1663 , ou encore les traités des moralistes et des confesseurs, tels que ceux de Juan Enríquez de Zuñiga, révèlent toute la difficulté de cette acculturation pour les couches moyennes de la société madrilène dans la pratique du conflit et l'exorcisme de l'homicide. Les acteurs du pardon de la partie offensée doivent se prononcer sur l'introuvable statut religieux du discours qu'ils veulent établir, autant que constituer l'apartamiento comme le lieu privilégié d'un hôpital du pardon chrétien, et l'envisager comme une véritable politique de l'exorcisme de la violence.

\section{L'INTROUVABLE STATUT D'UN DISCOURS RELIGIEUX}

\section{La restauration de l'amitié}

Pour le notaire grenadin du XVIe siècle, Diego de Ribera, l'écriture juridique d'amitié et celle du pardon privé se confondent car elles relèvent toutes deux d'une logique commune ${ }^{21}$. L'amitié, parce qu'elle constitue la métaphore

${ }^{20}$ Domingo DE Soto, De Iustitia et Iure, Madrid, rééd. 1967-1968 (1556), livre V, question V, p. 444.

${ }^{21}$ D. de RIBERA, Segunda y tercera parte de escrituras y orden iudicial, Madrid, 1617 (1564), f. 34. 
explicative de la concorde sociale, d'un point de vue idéologique, devient l'acte juridique de la restauration du lien social entre plusieurs personnes, et de ce fait, leurs familles. D'explicative elle devient prescriptive. Un acte de foi oblige les Madrilènes en litige à reconnaître la nature de leur dispute et son caractère judiciaire. Un soldat de la garde à Cheval, Joseph de Arriola, blesse en 1658 le caissier des entrées à la comédie et provoque une rixe générale. Son capitaine, Luis de Guzmán Ponce de León, réussit à obtenir le traitement de l'affaire et fait incarcérer l'inculpé dans la prison de la garde espagnole. Il use alors de son autorité pour pacifier les rapports entre l'accusé et sa victime. Selon le chroniqueur Diego de Soto y Aguilar, «huvo apartamiento y fee de fuera de peligro y amistades y fue absuelto sin condenación ninguna»22. La concession de l'apartamiento, dont la formule contient une demande de fin des poursuites, est première, puisqu'elle instaure le pardon de Domingo Pariz à son agresseur.

De ce fait l'offense privée peut être considérée comme réparée. L'acte de foi amicale, inséparable de la déclaration médicale sur l'état des blessures de la victime, n'est que second, mais il a l'avantage de perpétuer les conséquences du pardon octroyé par la partie offensée. Il transforme la réparation obtenue par Domingo Pariz en une nouvelle concorde entre ce dernier et Joseph de Arriola, qui se veut définitive. La concession de l'apartamiento ouvre la voie au pardon royal et à la rémission de la peine. La fe de amistad établit la fin de la querelle et garantit le bien commun. Dès lors que la tranquillité des bons sujets est assurée, selon Domingo de Soto, le Prince se doit d'accorder sa grâce ${ }^{23}$.

Andres Suarez concède un pardon à Juan et Martin de Cuevas, responsables du décès de son beau-frère Juan Martín en septembre 1642, et insiste tout particulièrement sur cette fonction pacificatrice. La pacification sociale consacre le rétablissement de l'amitié, considérée comme la condition première de toute coexistence collective. Le lien social est par là rétabli. Les familles, qui constituent la respublica madrilène, peuvent à nouveau vivre ensemble. Et il ne s'agit là qu'une des nombreuses formes de l'infrajustice qui, avec les paix, les concordias ou les avenencias que reconnaît la législation castillane depuis les Siete Partidas (12561265) d'Alphonse $X$, sont largement pratiquées par la société d'Ancien Régime en dehors de toute intervention de la monarchie catholique ${ }^{24}$.

22 D. DE Soto y Agullar, Tratado de los suceos que han tenido las guardas Españolas Amarilla Beja y de Acavallo del Rey nuestro Señor desde el rey Don Fernando el Catolico deste Nombre, 1663, f. 218 .

${ }^{23}$ Domingo DE Soto, De iustitia et iure, libro V, q. 4, art. 2.

${ }^{24}$ Les procédures d'infrajustice auxquelles se rattachent les pratiques de l'apartamiento et de la fe de amistades nécessitent l'intervention d'un tiers ou d'une institution sociale pour obtenir un règlement entre les parties en conflit qui a force d'obligation morale pour les parties et l'ensemble de la communauté menacée par le litige. Voir B. GARNOT, Justice et société en France aux XVIe, XVIIe, et XVIIIe siècles, Paris, Ophrys, 2000, p. 86; (dir), L'infrajudiciaire du Moyen Âge à l'époque contemporaine, Dijon, Editions Universitaires de Dijon, 1996. 
Ce pacte privé de l'amitié ne fonctionne pas toujours. En 1626, le doreur Juan de Cañeda tue Gabriel Alonso parce que ce dernier refusait de lui donner «la mano de amigo» 25 . Le 2 février 1662, un soldat de la garde Espagnole, Joseph de Morales, meurt en voulant pacifier une rixe ${ }^{26}$.

Pour durer la fe de amistad doit s'effectuer entre égaux ou dans le cadre d'un rapport de clientèle. Andres Suarez fait de l'amitié le fondement de la paix familiale. Il rappelle par ses paroles les liens de parentèle qui l'unissent aux agresseurs, se plaçant ainsi dans un rapport d'égalité avec eux. Ils appartiennent tous à la même famille et au même métier. C'est le point commun qu'ils partagent et à partir duquel la pacification de leurs relations, rendues tumultueuses pour une question de dettes, trouve sa justification. Le métier, l'atelier, l'appartenance à un corps considéré comme une maison commune, est l'autre cadre dans lequel l'acte d'amitié scelle la réconciliation entre les personnes. Andrès Suarez, Juan et Martin de Cuevas appartiennent tous les trois à l'univers des charbonniers de Madrid. Enfin, il existe un dernier cadre, celui du clientélisme, où le don de l'amitié peut s'exprimer. Joseph de Arriola accepte de faire un pacte avec sa victime dans la mesure où celui-ci est placé sous le patronage de son capitaine. Luis Guzman Ponce de León, en tant de gouverneur de la garde espagnole, se conduit avec «ses» soldats comme un père envers ses enfants, un patron envers ses clients. Cette attitude se rapproche de ce que les théologiens nomment la justice commutative ${ }^{27}$.

La référence évangélique constitue un exemplum largement utilisé par les juristes puisqu'elle enjoint aux hommes de pardonner celui qui les a offensés ou agressés dans le cadre d'une procédure pénale. Celle-ci représente le casus dans lequel la norme de l'exemplum doit être déplacée. Selon Hugo de Celso (1538), «El hombre que perdonare a aquel que lo boviesse offendido o injuriado haze limosna espiritual que es mejor que la corporal» 28 . Cela ne va pas sans censures.

Avant le procès, la victime mourante refuse de porter plainte et accorde son pardon à l'agresseur. Pour recevoir la paix du Christ, il faut purifier son esprit de la passion et de la colère. Le récit du pardon doit censurer «les phrases et les actes, la plaisanterie, les signaux et les gestes, les divers mouvements du corps» qui manifestent un comportement, lié à l'animalité et au poids corrupteur du corps sur l'âme. La censure de l'accord financier doit démontrer la gratuité de

\footnotetext{
${ }^{25}$ AGS, Camara de Castilla, legajo 2562.

${ }^{26}$ AGS, Camara de Castilla, legajo 2583.

27 J. DE Lugo, De iustitia et iure (1642), Clemente Fernández (sél.), Los filósofos escolásticos de los siglos XVI y XVII, Madrid, 1976, p. 1075.

${ }^{28} \mathrm{H}$. DE CELSO, Reportorio universal de todas las leyes destos reynos de Castilla, Madrid, CEPC, 2000 (1553), f. cclvij.

Hispania Sacra, LX

121, enero-junio 2008, 231-266, ISSN: 0018-215-X
} 
l'acte. Le moraliste Juan Enriquez de Zuñiga insiste sur la nécessité de cette imitation du Christ dans le pardon, et conclut «siendo Dios autor de la ley de perdonar injurias, se sigue por consequencia necessaria, que de qualquiera otra, que se quiera considerar contraria à esta, es fuerça, ser autor el demonio» 29 . Pardonner son agresseur, avant de rendre son âme à Dieu, revient à manifester publiquement, dans ses derniers moments, l'absence d'emprise satanique.

Pourtant le prédicateur de l'ordre de St Augustin, Juan Enríquez de Zuñiga, remarque en 1634, «aunque el hombre ofendido esta obligado a perdonar la injuria, no esta obligado a perdonar la satisfación de la injuria; y assi puede responder que perdona la injuria pero no la satisfación ${ }^{30}$. Les conséquences matérielles de l'offense subie exigent une réparation de même nature, capable de satisfaire en ce sens l'injure prononcée, qui n'engage pas le salut de l'âme de l'offensé puisqu'elles ne relèvent que de la cité des Hommes. Ainsi, Antonio Fernandez en 1663, en se limitant à pardonner ou excuser la seule offense physique, accomplit son devoir de chrétien et son devoir de famille ${ }^{31}$. Tout en pardonnant Lucas Collazo, il l'accuse d'être l'auteur de ses blessures aux jambes et affirme que l'agression s'est déroulée devant la porte du collège impérial. Il lave son âme, qui peut passer à tout moment de l'autre côté, du péché de colère ou de la passion de la vengeance et assure à ses héritiers la possibilité d'un procès pénal et le marchandage d'un nouvel apartamiento.

\section{Les censures de la référence évangélique}

La négociation de l'apartamiento, essentielle, car de son aboutissement peut dépendre la grâce du roi, dure parfois des mois, voire des années, et concerne aussi bien les accusés ou condamnés prévenus que ceux qui sont en fuite ${ }^{32}$. La question du dédommagement financier en représente le cœur pour des veuves et des familles, que le décès de la victime prive d'une source de revenus, brisant parfois toute une stratégie d'ascension sociale ${ }^{33}$. Le milieu social impliqué dans ces «accidents» ou ces «événements» dramatiques est celui de la medianía: gens de lois, officiers du roi, artisans, domestiques etc...

\footnotetext{
29 J. ENRIQUEZ de ZÚÑIGA, Consejos politicos y morales, Madrid, 1663 (1634), f. 48.

30 J. EnRiQueZ, Compendio de casos morales, Sevilla, 1634, f. 60.

${ }^{31}$ Archivo Historico de Protocolos (AHP), Hospitales, 10677, f. 268.

${ }^{32}$ Francisco Tomás y VALIENTE, «El perdón de la parte ofendida en el derecho penal castellano (siglos XVI, XVII y XVIII)», Anuario de Historia del Derecho Espagnol, XXXI, 1961, 55-114.

33 José Luis de Las Heras a calculé que la valeur moyenne du dédommagement financier des pardons de la partie offensée serait de 890 ducats pour la période 1560-1700 en oubliant toutefois d'évaluer ce chiffre à la lumière des fluctuations monétaires et de l'inflation. José Luis de Las HerAS SANTOS, «Indultos concedidos por la Camara de Castilla en tiempos de los Austrias», Studia Histórica. Historia Moderna, $\mathrm{n}^{\circ} 3$, vol. 1, 1983, 127.
} 
Pourtant cette négociation n'appartient pas qu'aux parties en litige. Elle est l'objet d'un débat entre juristes, moralistes et théologiens, pour lesquels une censure doit s'exercer sur les conditions économiques et sociales du discours de l'apartamiento. La question est alors de savoir comment les Madrilènes réussissent à exprimer, dans le discours de l'apartamiento, le résultat de la négociation et l'identité de ses acteurs (l'influence des avocats et des réseaux de parentèle et d'amis)? - Et ceci malgré une censure orchestrée par les juristes et la monarchie, afin que le pardon de la partie offensée soit une analogie parfaite de la grâce du roi et du pardon du Christ. Les Pouvoirs judiciaires et le Pouvoir monarchique sont ainsi amenés à négocier avec la société madrilène, dont ils espèrent une acculturation des mentalités judiciaires plus conforme à la police chrétienne de la cour d'Espagne. Cette politique du pardon débouche sur la mise en place de véritables modes de censure du discours de l'apartamiento

Le statut juridique et moral du pardon de la partie plaignante est complexe. Le discours du pardon privé est structuré -donc censuré- par la rationalisation en cours des écritures juridiques de l'Espagne des Habsbourg. Il faut d'abord mesurer le poids des practicas sur l'exercice des greffiers, notaires, avocats, et procuradores qui peuplent les tribunaux de la cour. La littérature des livres de pratique judiciaire propose un modèle de discours du pardon, à mi-chemin entre l'expérience professionnelle de son auteur (qui est un juriste) et la volonté des tribunaux de standardiser l'ensemble des actes judiciaires pour renforcer leur identité juridictionnelle. S'il n'existe pas de traité sur l'apartamiento à proprement dit, le thème n'en est pas moins présent dans de nombreux ouvrages de pratique judiciaire.

C'est ainsi que Juan Muñoz l'évoque à partir du rôle du procurador, qui rédige l'ensemble des écritures destinées au procureur pour le compte d'une des parties en litige sous la conduite de l'avocat, chargé d'élaborer la stratégie judiciaire globale de ses mandataires. Sa practica de procuradores para seguir pleytos civiles y criminales (1589) nous explique à quelles conditions une veuve peut faire rédiger un acte de pardon privé34. Une première censure apparaît: le pardonnant ne pourrait être qu'une veuve, dont le mari a été assassiné, et soucieuse du devenir de ses enfants. C'est en tant que tutrice (curadora) de ses enfants qu'elle détient ce pouvoir de pardon. Le discours élaboré doit affirmer le libre consentement de la veuve, c'est-à-dire proclamer par un serment que le pardon est libre de toute arrière-pensée, de toute méfiance envers la justice, de toute peur de la partie adverse. Le contexte social de la négociation du pardon est ainsi nié par le discours qu'il cherche à produire. La seule réalité sociale admise par le notaire est l'intérêt des enfants qui doit motiver l'apartamiento. Ce dernier

34 J. MuÑoz, Pratica de procuradores para seguir pleytos civiles y criminales, Madrid, 1659 (1589), f. 60.

Hispania Sacra, LX

121, enero-junio 2008, 231-266, ISSN: 0018-215-X 
doit être utile aux enfants. Faut-il entendre cette utilité dans un sens matérialiste ou strictement spirituel? Le juriste se garde bien de préciser les choses.

Le pardon privé est ensuite transmis au juge compétent, qui décide ou non, de l'enregistrer et de le joindre aux pièces du procès en cours ou déjà achevé. Il revient alors au prisonnier d'arrêter la procédure d'appel et de solliciter directement la grâce du roi. En 1690, l'avocat des conseils du roi, le licencié Juan López de Cuellar y Vega, confirme la validité de cette procédure dans son traité consacré au pardon royal. Il précise que «es necessario, que la parte injuriada perdone, para que el Reo en una, y otra Indulgencia del Principe, logre con plenitud su gracia, pues nunca es visto querer su Real Clemencia perjudicar à tercero» ${ }^{35}$. Si le roi n'a pas pour habitude de porter préjudice à une tierce personne, en oubliant de considérer l'obtention ou non d'un apartamiento en faveur du délinquant qui sollicite sa grâce, il ne faut néanmoins pas y voir une règle de droit systématique. Le juriste est sans ambiguïté sur ce sujet-là: «no necessita el Soberano del consentimiento de la parte» ${ }^{36}$. La grâce du roi est gratuite, donc libre en droit de tout consentement de la partie offensée. D'ailleurs, le roi ne s'exprime que sur l'offense publique, qui constitue le crime d'homicide à côté de l'offense privée, seul espace dans lequel l'apartamiento prendrait son sens moral et social.

Pour le greffier des alcades de cour en 1672, Geronimó Fernández de Herrera Villaroel, la justification du pardon privé d'un homicide se résume à trois éléments $^{37}$ :

- La nature du délit (état de la procédure, juge, parties en litige etc...).

- La renonciation au droit et aux procédures en cours contre l'accusé accompagné par une supplique adressée au roi pour qu'il gracie le criminel.

- L'obligation pour soi et les siens de respecter ce contrat.

La référence à Dieu et l'assurance que le contrat n'est pas conclu sous l'emprise de la crainte doivent conduire les juges vers une pieuse tolérance et les convaincre de ne pas poursuivre les poursuites engagées, ce qu'ils ont la possibilité de faire en droit ${ }^{38}$. C'est pourquoi en 1664 , le valet de la maison du roi, Francisco de Alcaria, utilise le pardon que lui a octroyé le père de la victime, Domingo de Yuncos, pour influencer le jugement que doit prononcer la junte royale du Bureau le 6 décembre 1664 sur une accusation d'homicide ${ }^{39}$. Accusé

35 J. López de Cuellar y Vega, Tratado Iuridico, Politico; Practica de indultos, Pamplona, 1690, p. 14 .

${ }^{36}$ Idem, p. 15.

37 G. Fernández de Herrera Villaroel, Practica criminal instruccion nueva util de substanciar las causas, Madrid, Imprenta real, 1672, t. II, p. 367.

38 «facilitan el animo de los juezes a la piedad con la manifestacion que hazen, de que les consta la integridad con que procedieran si quisiesse continuar en el litigio»,Idem.

39 Archivo General del Palacio real (AGP), Fondo juridico, caja 54/4. 
d'avoir tué Gonçalo de Yuncos avec un chandelier, Francisco de Alcaria est condamné, à compter du 6 décembre 1664, à 4 ans de service dans un préside d'Afrique et au bannissement de la cour et des six lieues alentour, par le comte de Montalban, le marquis d'Arria, celui de Guardias et celui de Martealegre. Le pardon privé n'implique néanmoins pas un arrêt systématique des poursuites pénales selon Geronimó Fernández de Herrera Villaroel. Aucune place ne semble laissée à l'accord financier car la déclaration d'un pardon payant pour toute sentence non corporelle a valeur d'aveu selon la loi 22 des Siete Partidas.

\section{Dire l'accord financier ou briser le tabou}

Geronimó Fernández de Herrera Villaroel admet, cependant, un cas pour lequel le marchandage doit être explicité dans le discours de l'apartamiento. L'accusé contre lequel il n'existe pas de preuve complète de sa culpabilité peut négocier l'apartamiento des plaignants. Le juriste affirme alors que dans ces conditions ${ }^{40}$, l'accusé n'achète pas le pardon des victimes mais le retrait de la plainte, c'est-à-dire le droit qu'ont ces dernières de le poursuivre pénalement devant un tribunal. L'accusé négocie donc le prix d'une procédure inutile puisque le discours le déclare innocent du crime que les juges lui imputent ${ }^{41}$. L'acte de pardonner n'est pas concerné par la négociation financière.

Il demeure pur de toute altération marchande et répond d'autant mieux aux exigences des moralistes. La réparation financière n'est certes pas condamnée en soi par les moralistes. Le prédicateur de l'ordre de Saint Augustin, Juan Enriquez de Zuñiga, affirme en 1634 que «hombre que a muerto a otro, està obligado a satisfazer todos los daños que hizo con el homicidio, a las partes que quedaron ofendidas: y esta satisfacion se a de hazer segun el arbitrio del prudente varon, el qual deve mirar las circunstancias de el daño causado en el homicidio. $\mathrm{Y}$ assi, si un hombre matasse a un oficial que ganava cada dia ocho reales con que sustentava su casa», il a le devoir de fournir une réparation équivalente à la famille de la victime ${ }^{42}$. Mais cette réparation ne peut, dans l'esprit de la contre-réforme catholique, motiver l'acte de pardon proprement dit. L'influence du modèle de la confession auriculaire renforcée par le concile de Trente (1545-1563) pour réaffirmer le rachat des fautes par l'acte de pénitence sem-

\footnotetext{
40 G. FernándeZ de Herrera Villaroel, Practica criminal, p. 364.

41 «comprando al interessado la accion que (el querellante) tenia contra el reo, se salvara la contraria objeccion con poder probarse por el instrumento, y protesta de que el precio que diò fue por librarse de la molestia de el pleito, y no serà avido por consejo, aunque presente semejante apartamiento, en que intervino interès», idem, p. 364.

42 J. EnRiQueZ de ZúNiga, Compendio de casos morales, Madrid, 1634, f. 62.
}

Hispania Sacra, LX

121, enero-junio 2008, 231-266, ISSN: 0018-215-X 
ble ici déterminante ${ }^{43}$. La réparation des maux causés par l'homicide doit manifester la volonté sincère d'une réconciliation du délinquant avec Dieu et l'imitation de la charité christique du plaignant. D'une manière implicite ou non, chacune des parties s'adresse à Dieu avant autrui. Dans l'énoncé, la dialectique du péché semble première sur celle de l'arrangement judiciaire.

Le jésuite Juan Eusebio Nieremberg (1595-1658) donne dans le cinquième livre Del aprecio y estima de la gracia divina (1638) une définition de la mort en grâce qui explique certaines censures du discours de l'apartamiento. Le cinquième signe de cette mort en grâce, proposé comme modèle, se fonde sur la libération de l'esprit des biens matériels et terrestres, et correspond à la censure de l'accord financier ${ }^{44}$. La victime mourante, ou la famille du mort, ne peuvent lever le tabou que pour les sommes d'argent destinées aux messes pour le salut du défunt ou à l'entretien des enfants. On ne négocie la réparation matérielle de l'offense que pour autrui. L'esprit de l'auteur du pardon semble donc rester libre des biens de ce monde.

Le poids des juristes et des moralistes laisse cependant échapper des récits d'accord financiers qui structurent une minorité d'apartamientos (qui n'en sont pas moins significatifs) ${ }^{45}$. Ce sont ces exemples que je me propose d'étudier maintenant.

Ana et Geronima del Bal reconnaissent en 1642 pardonner à Juan Montes la mort de leur frère le doreur Luis del Bal, parce que la mère de l'accusé Lucia de Olmos leur a donné «cien ducados de plata en un censo que tiene contra las personas y vienes de Alonso Hernandez y Maria Lopez su muger», afin de subvenir aux frais du procès engagé ${ }^{46}$. Il est vrai que la procédure pénale engagée devant les alcades de cour se poursuit depuis 1636.

La présence de mineurs parmi les représentants de la partie offensée permet aussi de révéler le prix de l'accord: les enfants du colonel Diego Ruiz reçoivent en 1637, par l'intermédiaire du notaire Pedro de Cantalero, 800 réaux de billon de l'inculpé Juan de Cesar ${ }^{47}$. Cette situation est admise par les juristes depuis le

43 J. Delumeau, L'aveu et le pardon. Les difficultés de la confession XIIIe-XVIIIe siècle, Paris, Fayard, 1964.

44 «La quinta señal es la pobreza de espíritu, despegando el corazón de los bienes de la tierra; y así, a la primera de las Bienaventuranzas, que es ser pobre de espíritu, se promete el reino de los cielos. Y Cristo escogiò en este mundo los pobres, y contra los ricos pronunció notables y bien temerosas sentencias ...», J. EuSEBIO NiEREMBERG, Del aprecio y estima de la gracia divina, Madrid, reed. 1957, vol. I, p. 441.

45 Une étude du prix des pardons de la partie offensée a été menée pour un cas comparable au nôtre, celui de Jaen. Angel ApOnTE MARín, «Apuntes sobre la delincencia en Jaen en la primera mitad del siglo XVII», Chronica Nova, n¹5, 1986-1987, 9-16.

46 AGS, Camara de Castilla, legajo 2570.

${ }^{47}$ AGS, Camara de Castilla, legajo 2568. 
XVIe siècle pour les enfants de moins de 25 ans. Le modèle que propose Diego de Ribera dans la réédition de ses Escrituras de 1617 l'atteste ${ }^{48}$.

Faria de Arguello reçoit en 1632, pour son pardon, et au profit de ses fils mineurs, 350 ducats comptants de Jusepe Hidalgo qui tua son mari Juan Bautista avant de s'enfuir ${ }^{49}$. Jusepe Hidalgo s'engage en outre à verser en faveur de la partie plaignante 100 ducats de plus dans les deux années qui suivent. Le 20 septembre 1667, la veuve d'Andres Sanz de Guerra, Ana y Alban obtient de l'assassin de son mari, Juan Chico Cebrian, 200 ducats de billon pour l'entretien de son fils ${ }^{50}$. Antonio de la Riva représente, entre 1620 et 1622, les intérêts de toute la famille de Juan Bustamente assassiné par Alonso Zumbron. Il obtient, pour le pardon concédé par ses mandataires, 60 ducats comptants de l'accusé. L'ensemble des membres de la famille adhèrent à cet apartamiento, y compris les enfants mineurs ${ }^{51}$.

Maria Luys Gonçalez, veuve de l'huissier de la ville Domingo Macias assassiné par les frères Simon et Francisco Salces en 1636, reconnaît, dans le pardon qu'elle octroie aux accusés dix années plus tard, avoir reçu de leur part 2300 réaux de billon au comptant au profit de ses filles ${ }^{52}$. La veuve Antonia de Valbende reconnaît dans l'apartamiento signé le 15 février 1653 que les 100 ducats de billon versés par Alonso Rubio, coupable du décès de son mari Miguel Vallejo, le sont pour ce seul motif ${ }^{53}$. La somme remise est un dédommagement pour les conséquences matérielles qu'a entraînées la mort de Miguel Vallejo dans la vie de son épouse. C'est sans doute le seul apartamiento dans lequel le fondement économique du pardon est aussi clairement revendiqué.

Le récit de l'accord financier ne trouve pas seulement son sens par rapport aux vivants. Il peut être lié à la place du mort en tant que tel dans la société du XVIIe siècle et rejoindre les principes catholiques de l'économie du salut. Ana Mahona, devenue veuve d'Antonio de Mezquina lorsque Juan Martín tua ce dernier au mois d'avril 1662, fait écrire par son notaire le 9 décembre de la même année, qu'elle pardonne l'assassin de son mari «porque a recivido tres-

\footnotetext{
48 «Y porque el dicho Pedro por redemir su vexacion, v porque el dicho Iuan menor se aparte de la dicha querella, y le perdone su daño, è injuria, dize que le dara y pagarà cien ducados, lo qual assi a el como al dicho su curador les ha parecido que le es expediente y util acetar, por evitar las costas y gastos que demas de las hechas se podrian seguir, y porque el fin y sucesso de los pleytos es vario, y dudoso, por tanto en aquella mejor via y forma que de derecho aya lugarpidio al Señor Alcalde mayor, dè licencia para poderse apartar de la querella y acusación que està dada del dicho Pedro, è interponga en el dicho apartamiento y perdon su autoridad y decreto judicial, y pidio justicia, y en lo necessario implorò su oficio», D. de RIBERA, Escrituras ..., f. 35.

${ }^{49}$ AGS, Camara de Castilla, legajo 2565.

${ }^{50}$ AGS, Camara de Castilla, legajo 2585.

${ }^{51}$ AGS, Camara de Castilla, legajo 2556, f. 173.

52 AGS, Camara de Castilla, legajo 2571.

${ }^{53}$ AGS, Camara de Castilla, legajo 2575.
}

Hispania Sacra, LX

121, enero-junio 2008, 231-266, ISSN: 0018-215-X 
cientos reales para decir misas por el dicho su marido por mano de un religioso del conventto de nuestra señora del Carmen» ${ }^{54}$.

Mais la majorité des pardons où l'échange monétaire est signifié ne contiennent aucune justification pour exorciser la levée de l'interdit. Le plus difficile pour la partie offensée semble être de briser l'interdit lui-même plus que de construire une légitimation a posteriori de l'acte. L'épouse du défunt Gregorio Torres, alguazil de ville, Ana Ybañez, agit ainsi le 7 février 1629 avec l'inculpé du meurtre de son mari, Lorenzo Quintana. Elle se contente de faire mentionner dans son apartamiento que Lorenzo Quintana lui a versé 500 réaux de billon ${ }^{55}$. Les 600 réaux que reçoit, le 30 mars 1641, l'oncle de Gabriel de Salinas de la part de l'assassin de son neveu, Juan Ambite, poursuivi par la justice du corrégidor, sont mentionnés comme une information neutre dans le discours du pardon correspondant ${ }^{56}$.

Les parents de Joan Rodríguez adoptent une attitude similaire, en signalant les 200 réaux reçus, dans le pardon qu'ils accordent à Francisco Fernández le 4 février 1651. Ils font en effet écrire au notaire que l'accusé leur donnera cette somme sans plus de précision ${ }^{57}$. Le père de Vicente Sorcela qui reçoit le 11 décembre 1664300 ducats de Manuel Ercilla et Ignacio Torres, poursuivis par le tribunal de cour pour le meurtre de son fils, n'est pas explicite ${ }^{58}$.

La somme augmente avec la qualité de l'accusé et du délit. A la fin du mois d'octobre 1663, Juan Gonçalez tombe sous le coup d'épée que lui donne, dans le dos, le majordome de la marquise de Santa Cruz. La lâcheté de l'acte comme le rang social de Jacinto Amezaga, nous explique sans doute pourquoi il verse à la veuve de sa victime pas moins de 7000 réaux $^{59}$.

Les acteurs de la négociation sont souvent regroupés sous l'expression de «personnes honorables» qui auraient conseillé le plaignant d'accorder son pardon à l'accusé ou au condamné. Néanmoins, certaines victimes laissent percevoir dans leur récit de justification du pardon accordé les procédures infra-judiciaires qui ont permis la négociation financière.

Dans l'affaire de l'assassinat de l'ouvrier maçon Andres de Mezquiza, c'est un religieux du couvent de Notre Dame du Carmel qui semble jouer le rôle d'arbitre. Le meurtrier présumé, Juan Martinez Gobierno -qui est lui maître maçon- ne peut négocier directement puisqu'il est en fuite et doit se cacher. Sa

\footnotetext{
${ }^{54}$ AGS, Camara de Castilla, legajo 2580, f. 47.

55 AGS, Camara de Castilla, legajo 2560.

56 AGS, Camara de Castilla, legajo 2569.

${ }^{57}$ AGS, Camara de Castilla, legajo 2575, f. 12.

58 AGS, Camara de Castilla, legajo 2581, f. 87.

${ }^{59}$ AGS, Camara de Castilla, legajo 2581, f. 69.
} 
position sociale lui permet cependant d'arriver à un accord assez vite: la procédure pénale est établie dès le 17 avril 1662 et l'apartamiento de la veuve, signé le 9 décembre $1662^{60}$. Entre ces deux moments, il a fallu attendre le décès du blessé qui, le 18 avril, était encore vivant. L'appartenance à un même groupe social facilite la négociation.

Dans le procès d'Alonso Zumbron (1620-1622), poursuivi pour le meurtre d'un valet, Juan Bustamente, au sortir du théâtre, l'influence du maître de la victime, Fernando de Toledo, semble déterminante ${ }^{61}$.

Le procès engage généralement toute la famille. C'est la mère de l'accusé (l'ébéniste Juan Montes en fuite), Lucia de Olmos, qui, entre 1636 et 1642, négocie l'apartamiento avec toute la famille de la victime, les deux sœurs (Ana et Geronima del $\mathrm{Bal}$ ) et le frère de ce dernier. Le prix (100 ducats d'argent) est d'autant plus lourd que le milieu social de la victime est important, l'orfèvrerie. Mais le savetier Juan Ambite négocie directement de la prison de ville, où la justice du corrégidor l'a incarcéré, avec l'héritier de l'étranger qu'il a tué à la suite d'un échange d'insultes dans la rue de la Paloma en 1636. La difficulté vient, cette fois-ci, du statut de la victime Gabriel de Salinas. Il faut d'abord que les autorités judiciaires retrouvent l'oncle de la victime qui ne concède son pardon que le 30 mars 1641, sur le conseil de «personas religiosas» ${ }^{62}$.

$\mathrm{Au}$ moment de rechercher la somme nécessaire au pardon, les amitiés et les liens de clientèle sont essentiels. Jacinto Amezaga poursuivi pour le meurtre de Juan González survenu à la porte de San Bernardo par les alcades de cour depuis le 20 octobre 1663, doit son salut au majordome de la marquise de Santa Cruz qui donne 7000 réaux à la veuve pour obtenir son pardon ${ }^{63}$. Simon et Francisco de Salces, poursuivis pour le meurtre de Domingo Macias, l'huissier à verge de Madrid, le 15 septembre 1646, possèdent une boutique où ils vendent de l'huile, du vinaigre et des légumes dans la rue Palmora. Leur incarcération ne peut que nuire à leur commerce qui par ailleurs leur assure un revenu suffisant pour négocier rapidement l'apartamiento de la veuve Maria Luys Gonçalez qui, elle, ne peut attendre puisqu'elle a des filles à charge. Aussi l'accord est-il conclu dès le 12 janvier $1646^{64}$.

Le rôle de l'accord financier dans le discours de l'apartamiento en bouscule les structures fonctionnelles et formelles. Cas limite, il oblige les acteurs du discours à révéler leurs choix de langue, de détails et d'ordre et nous permet de mieux comprendre cette technique particulière de la narration du crime et de

\footnotetext{
60 AGS, Camara de Castilla, legajo 2580, f. 47.

${ }^{61}$ AGS, Camara de Castilla, legajo 2556, f. 173.

62 AGS, Camara de Castilla, legajo 2569.

${ }^{63}$ AGS, Camara de Castilla, legajo 2581, f. 69.

${ }^{64}$ AGS, Camara de Castilla, legajo 2571.
} 
ses enjeux sociaux. Le discours du pardon privé ne s'adresse pas seulement au délinquant supposé ou condamné, il est aussi une supplique faite au roi, assimilable en cela aux lettres de rémission du royaume de France ${ }^{65}$. La portée de l'accord financier déborde donc le cadre de l'offense privée au profit de l'espace public. L'apartamiento est offert au roi comme l'instrument capable de légitimer le retour de l'ordre, qu'incarne l'actualisation de sa puissance de grâce.

La description de la négociation financière, parfois limitée à une simple référence, est le produit de la collaboration entre les trois acteurs du discours: le letrado, la partie plaignante et l'accusé. Cette collaboration est au service d'une censure du discours dont la monarchie cherche à maîtriser les pouvoirs de pacification. Les tribunaux du roi et Philippe IV doivent rester les arbitres suprêmes des conflits qui opposent les familles madrilènes. La métamorphose du récit de l'accord financier en un objet-tabou, organisée à partir de l'instrumentalisation de la théorie de la justice des moralistes et des théologiens, leur permet d'espérer contrôler la procédure du pardon privé et de s'y maintenir comme l'un des acteurs principaux. Il s'agit de forcer l'adhésion des parties en litige au rôle social des hommes de loi au détriment d'arrangements extrajudiciaires, parfois violents. Avec l'accord financier, qu'implique tout acte d'apartamiento, les tribunaux du roi tentent d'intégrer les règlements infrajudiciaires au système juridique officiel. Pour cela, les juristes notamment dans la littérature des Practicas ont forgé une véritable discipline pour contrôler la production du discours du pardon privé. Nous avons vu comment Geronimo Fernández de Herrera Villaroel en 1672, et d'autres avant lui, témoigne d'une volonté des letrados soutenue par la monarchie catholique d'imposer aux justiciables les règles d'une véritable police discursive 66 . Le récit de l'accord financier n'est toléré que si des intérêts extérieurs à ceux de la personne qui pardonne peuvent le justifier.

Notons, à ce propos, que seules les veuves du monde des métiers pratiquent cette censure. Dès lors que les parties en litige appartiennent à des groupes sociaux plus aisés ou plus prestigieux (l'univers de la robe et de l'épée), les sommes échangées, quand elles sont inscrites dans le récit, le sont sans aucun commentaire justificateur. Le tabou de l'accord financier est brisé pour être tout de suite neutralisé, puisque aucun argument n'est établi pour le relier à la rhétorique globale de l'apartamiento. Leur apparition dans le discours ne doit pas compromettre la philosophie catholique du pardon judiciaire alors que celui-ci, au travers de diverses formules (l'expression de «personnes honorables et pieuses»), est dans l'obligation de se référer aux liens d'amitié et de clientèle, qui seuls garantissent l'efficacité de l'apartamiento et la fin de la violence que le juge cherche à obtenir. La négociation extrajudiciaire des réparations de l'ho-

${ }^{65}$ N. ZeMOn DaVIS, Pour sauver sa vie. Les récits de pardon au XVIe siècle, Paris, 1988.

${ }^{66}$ M. Foucault, L'ordre du discours, Paris, Gallimard, 1971, p. 37. 
micide, où interviennent les individus directement engagés, leurs familles, les corps sociaux auxquels ils appartiennent, est donc révélateur d'une pratique marchande, non assumée, qui met en cause les rapports de pouvoir entre le monarque, les letrados, et les justiciables.

La censure du récit de l'accord financier et ses divers degrés nous permet ainsi de reconstituer le processus de négociation qui conduit à la résolution du conflit. Celle-ci doit donc être étudiée à partir de l'évaluation de l'efficacité du pardon de l'homicide que peuvent en faire les juges compétents: le corrégidor, les alcades de cour, les membres du conseil de la Chambre de Castille. Il faut la considérer comme un des éléments majeurs des modes de discipline de la société d'Ancien Régime ${ }^{67}$.

\section{MATER DOLORIS, L'HÔPITAL DU PARDON CHRETIEN}

\section{Une stratégie testamentaire}

Les testaments rencontrés dans les fonds d'archives des hôpitaux madrilènes proviennent surtout des chefs de foyer, et ils incarnent une parole masculine (seuls les cas de 2 veuves y font exception).

Les testaments des blessés des hôpitaux sont hantés par l'économie du salut. Leurs auteurs se retrouvent de ce fait pris dans un ensemble d'obligations parfois contradictoires. Ils ne peuvent déposer une plainte auprès des notaires au risque de compromettre le salut de leur âme par le soupçon de leur soumission à l'état de colère c'est-à-dire l'un des 7 péchés capitaux, qu'implique cette procédure. La voie de l'apartamiento leur est donc interdite puisqu'elle sous-entend très souvent une plainte. D'un autre côté, il leur faut se placer dans l'imitation du Christ et donc en situation de pardonner l'offense qu'ils ont dû subir. De la même manière, ils doivent chercher à poser les bases d'une réparation des dommages produits pour leur famille et permettre à ceux qui la dirigeront après leur décès d'intenter un procès réparateur. Ils se doivent de construire un récit du crime et une description du criminel. L'auvergnat Juan d'Arc excuse le geste de Domingo García qui l'a blessé avec une pierre en 1634.

L'acte de pardon peut aussi conduire le mourant à minorer le crime commis. Alonso Martínez raconte le coup d'arquebuse qu'il a reçu de son valet comme un accident de chasse pour mieux l'excuser. Luis Fernandez lie son empoisonnement alimentaire à une erreur involontaire de sa femme Maria de Guzmán

${ }^{67}$ Tomás A. Mantecón Novellan, «Desviación, disciplina social e intervenciones judiciales en el antiguo régimen», Studia Histórica. Historia Moderna, vol. 14, 1996, 223-248.

Hispania Sacra, LX

121, enero-junio 2008, 231-266, ISSN: 0018-215-X 
qu'il excuse. Les livres de morale chrétienne castillans insistent sur l'oubli que doit savoir pratiquer le bon époux envers les fautes de sa femme pour mieux les mépriser. Par exemple, Juan Enríquez de Zuñiga conseille au mari «es que nunca te acuerdes de los disgutos, que te huviere dado tu muger: pues de las injurias es unico remedio el olvido, como dize Seneca» ${ }^{68}$. Ces conseils moraux prennent une valeur plus grande dès lors que le mari se sent mourir, comme Luis Fernández. En oubliant la culpabilité de son épouse et son droit de vengeance, Luis Fernandez se place dans l'imitation du Christ pour «vencer su propia passion» et prépare mieux encore son âme à la quête du salut ${ }^{69}$.

Dans certains cas, il s'agit de transformer la nature du crime jusqu'à en nier la qualification. Quand le mourant ne peut nier la gravitée de la blessure, il essaie de métamorphoser l'image du criminel. La moitié du texte du testament dicté par le Basque Pantaleon de San Roman, le 28 juillet 1633, est consacrée au procès pénal qui l'oppose à son agresseur le grand sacristain du couvent hiéronymite de la Conception, le licencié Vallador, devant le tribunal du vicaire. Pantaleon de San Roman, préalablement désigné comme un blessé en «peligro de muerte», «a descargo de su conciençia» 70 .

Cette stratégie testamentaire s'étend parfois aux parents de la victime. La lecture des demandes de pardon du Vendredi Saint vient alors compléter celle des testaments et déclarations des blessés soignés dans les hôpitaux madrilènes. Une servante qui travaille dans la maison de Balthasar de Fuenmayor, Ynes Rodríguez, est violemment assassinée par son mari, Domingo Vázquez en 1669. La difficulté des maris à exercer leur juridiction sur leur épouse est souvent soulignée par les moralistes. Dans ses Consejos politicos y morales de 1663, Juan Enríquez de Zuñiga reconnaît ainsi que «No es accion facil el perdonar las injurias, pues mas, que ellas, provoca à la vengança la propia passion del que se dà por ofendido. Y es tan natural esta passion en lo fragil de nuestra humanidad, que aun la sangre del justo Abel, despues de èl muerto, no se viò libre della, pues pidiò à vozes vengança à Dios contra Cain» ${ }^{71}$. Le décès d'Ynes Rodríguez est donc un accident de la colère des hommes. Les acteurs de l'apartamiento préfèrent donc ne pas la commenter. Selon Diego Pérez de Valdivia les passions conduisent l'homme vers les 7 péchés capitaux qui sont du point de vue de l'âme des péchés mortels ${ }^{72}$. La colère est l'un d'eux. C'est pourquoi elle est censurée dans la narration du pardon privé.

68 J. EnRIQUEZ DE ZúÑIGA, Consejos politicos y morales. Dividida en dos partes. Los de la primera tratàn de la vida Politica en general. Los de la segunda de lo tocante al govierno de un Iuez, Madrid, 1663 , f. 46.

69 Idem, f. 47.

${ }^{70}$ AHP, Hospitales, 24772, f. 82-85v.

71 J. ENRIQUEZ DE ZÚÑIGA, Consejos politicos y morales, f. 46.

72 Diego PÉrez de VAldivia, Aviso de gente recogida, Madrid, reed. 1977, pp 188-191. 
La victime n'avait plus qu'un frère Juan Rodríguez, maître savetier, originaire du Valle de Monterrey, qui porte plainte contre Domingo Vazquez et meurt quelques mois plus tard. Poursuivi par les alcades de cour, Domingo Vázquez se réfugie au Portugal mais sait qu'il n'a pas les moyens financiers d'un long exil. En 1670, il sollicite auprès de la Chambre de Castille (Camara de Castilla) la grâce du roi sans avoir obtenu un acte d'apartamiento proprement dit. Plus précisément, l'acte d'apartamiento qu'il présente aux greffiers de la chambre de Castille est inclut dans la copie du testament de Juan Rodriguez. Le frère de la victime écrit en effet dans son testament daté du 19 décembre 1669 « por serviçio de dios nuestro señor y que su divina Magestad me perdone mis culpas y pecados y haver me lo pedido personas de obligaçion le rremito y perdono» ${ }^{73}$. Le pardon du crime conjugal de Domingo Vazquez se trouve ainsi intégré à l'économie du salut d'un étranger au couple, le frère d'Ynès Rodríguez. L'assassinat d'Ynès Rodríguez est devenu une monnaie d'échange entre deux saluts: le salut spirituel du frère Juan de Rodríguez et le salut temporel du mari violent, Domingo Vázquez.

\section{Le pardon au féminin}

Les déclarations d'apartamientos portent souvent la voix des femmes meurtries. Leurs récits dominent l'ensemble de la masse documentaire des déclarations indépendantes. En 1647, Catalina Agua présente sa blessure à la tête comme le produit d'un accident, la chute d'un morceau de bois sur le lieu de son travail de servante ${ }^{74}$. La négation du crime n'est pas toujours effective. Le 18 octobre 1652, la veuve de Domingo Alvarez, Marta Ortega, désigne le responsable des violences subies, un certain Domingo Díaz avant de l'excuser ${ }^{75}$. A partir du moment où la déclaration se veut porteuse d'une stratégie de pardon, elle prend le risque de se confondre avec un acte juridique bien précis, l'apartamiento. Clara de Montoya pardonne, le 14 août 1653, Benito Menasco désigné comme l'auteur des blessures qui l'ont conduite à l'infirmerie de Saint Jo$\mathrm{seph}^{76}$. L'emploi du verbe apartar est justifié dans son récit par le rappel de l'existence d'une plainte déposée contre l'accusé. Dans le cas de Maria Ortega, l'absence d'une référence à un procès criminel en cours semble impliquer l'emploi du verbe exculpar. L'acte de charité chrétienne, que manifeste ce geste, demeure dans la seule sphère familiale et ne prétend pas directement à une valeur juridique. Cette situation n'interdit évidemment pas aux héritiers de ces blessé-

\footnotetext{
73 AGS, Camara de Castilla, legajo 2588.

${ }^{74}$ AHP, Hospitales, 24773, f. 14, 24, 26.

75 AHP, Hospitales, 8868, f. 759.

${ }^{76}$ AHP, Hospitales, 8869, f. 113 et 113v.
}

Hispania Sacra, LX

121, enero-junio 2008, 231-266, ISSN: 0018-215-X 
es d'essayer ensuite de revendiquer une portée juridique pour ces actes. Il s'agit de distinguer les différents usages possibles des pardons contenus dans les déclarations des personnes agonisantes aussi bien par leur auteur que leurs héritiers.

En 1659, Maria González, une femme célibataire alitée à l'infirmerie de Saint Joseph, explique comment à la porte d'Atocha, Jacinto Gómez qu'elle n'avait pas salué, le lui reprocha avant de « tratar mal de palabras y de uno en otra se enfurezio en colera y la dio de palos con la dicha orca que tenia en las manos» ${ }^{77}$. La mention de l'état colérique du criminel renforce le péché de son forfait. Il dote en conséquence le pardon octroyé par Maria González d'une valeur surajoutée. Plus le crime est grave, plus il est difficile à l'offensé d'échapper à la tentation de la vengeance et de la haine. Plus le délit compromet le salut de l'âme du délinquant, plus son pardon lui est nécessaire. Cette valeur supplémentaire est d'autant plus importante que la colère n'est pas décrite dans l'apartamiento du 19 septembre 1659 comme un état passager mais permanent. Maria González fait en effet écrire, à la suite du récit de sa rencontre avec Jacinto Gómez, que celui-ci continua à la battre après ces événements à plusieurs reprises.

Dans l'apartamiento du 5 août 1662, l'Asturienne Dominga García pardonne Ana Barragan qu'elle avait d'abord dénoncée comme l'auteur de certains coups $^{78}$. Tout en accordant l'acte du pardon, elle reconnaît l'inexistence du corps du délit: les coups reçus. En réalité, la contradiction n'est qu'apparente. Le discours fait référence à l'existence d'une dénonciation judiciaire et donc probablement à un procès pénal en cours. L'acte d'apartamiento, parce qu'il est en premier lieu adressé au juge, a son utilité. Plus que le sens du geste, c'est la valeur juridique qu'il nous faut ici considérer: mettre fin à une procédure pénale par l'équivalent d'un retrait de plainte. La négation des faits délictueux justifie cet objectif propre à l'apartamiento. Dominga García veut établir l'innocence d'Ana Barragan auprès du tribunal en pardonnant une innocente.

\section{Le drame des sans pardons}

La dramatisation du discours de l'apartamiento transcende son premier objet pour se répandre dans l'ensemble des stratégies discursives du condamné ou de l'accusé qui sollicite la grâce royale. Rares sont les sans pardons à se présenter devant le roi. Parmi eux, Pedro Rodriguez et le soldat de la garde espagnole, Felipe Zurdo semblent être, en 1666, des cas isolés ${ }^{79}$. Pedro Rodriguez est

\footnotetext{
77 AHP, Hospitales, 8870, f. 240.

78 AHP, Hospitales, 10678, f. 84.

${ }^{79}$ AGS, Camara de Castilla, legajo 2583.
} 
poursuivi par le corrégidor de Madrid pour la mort de Domingo Esteban survenue à la suite d'insultes. La procédure pénale intentée contre Felipe Zurdo est dirigée par le lieutenant du corrégidor Juan González de Lara. Arrêté pour le meurtre du cocher Juan Mallorquin, le soldat est incarcéré dans la prison de ville puis torturé. Pedro Rodriguez et Felipe Zurdo ont un point commun: ils sollicitent le pardon royal sans présenter d'apartamiento ni d'explication sur cette absence.

Felipe Zurdo présente un recours en grâce alors que l'instruction de son procès pénal n'est pas achevée. La rapidité de son geste explique sans doute l'absence d'apartamiento. Il n'a pas eu le temps de le négocier ${ }^{80}$.

Rien ne nous indique que le roi ou la reine mère aient été sensibles à leur requête. Ont-ils cru bénéficier de suffisamment d'appuis à la cour d'Espagne ou parmi les juristes du Conseil de la Chambre de Castillepour voir leurs noms présentés au roi? Ce silence ne suffit pas toujours à faire oublier l'absence de pardon. En 1640, le porteur d'eau Hernando Ruiz Pérez se sent obligé de justifier cette absence dans son recours en grâce présenté au conseil de la Chambre de Castille ${ }^{81}$. Il est poursuivi par les alcades de cour pour le meurtre de Pedro Rodriguez perpétré le 23 février 1639 à la suite d'insultes, et dont la victime est morte de ses blessures à l'Hôpital Général. Ce dernier n'ayant ni héritier ni parents, Hernando Ruiz Pérez n'a pu obtenir le pardon souhaité. Pour attester de cette absence de famille, il présente un certificat, affirmant que par trois fois le crieur de l'autorité judiciaire avait appelé sur les principales places de la ville un éventuel parent en vain. Hernando Ruiz Pérez semble donc victime de l'anonymat urbain.

Lazaro Alvárez ressent le même besoin d'expliquer cette absence dans le recours en grâce qu'il entreprend en 1670. Il «dice que se le ymputa (sin tener culpa alguna) la muerte de Juan Baptista Bolonia muchacho de poca edad amigo y compañero suyo por que ambos serbian al marques de Zeralbo; el qual le trujo de Flandes a esta corte siendo muy niño el dicho Juan Bautista bolonia: y por que a mi derecho conbiene por tratar de yndultar le y el dicho Juan bautista no tiene en estos reynos de España Padre ni Madre muger ni otro pariente alguno que le pueda ser ynteresado en esta caussa: y por esta razon ser seguido solo de ofiçio de justicia ni tanpoco se sabe de que lugar sea natural en los estados de Flandes con que es ymposible traer perdon de parte lejitima» ${ }^{82}$.

La recherche du pardon de la victime et de sa famille est un impératif moral. C'est d'abord le caractère violent de l'homicide qui oblige la demande du par-

\footnotetext{
${ }^{80}$ Idem.

${ }^{81}$ AGS, Camara de Castilla, legajo 2569.

${ }^{82}$ AGS, Camara de Castilla, legajo 2587.
} 
don privé83. Les propos déjà cités de Juan Enríquez de Zuñiga, de l'ordre de Saint Augustinle confirment. L'absence d'apartamiento implique pour la monarchie le refus d'une réparation financière alors que les conditions idéologiques du discours excluent sa signification. C'est là l'une des contradictions du discours de l'apartamiento. Quand le délinquant peut en présenter un, il ne doit généralement pas signifier l'accord financier qu'il a conclu avec la victime. Lorsqu'il n'est pas en mesure de présenter cet acte d'apartamiento aux conseillers de la Chambre de Castille, il leur laisse à penser qu'il n'a pas été capable de réparer l'offense privée provoquée par son homicide. C'est pourquoi Lazaro Alvárez se sent obligé de justifier cette absence, dramatique d'un point de vue moral et d'un point de vue juridique puisqu'elle remet en cause la légitimité de son recours en grâce.

Dans de très rares cas le délinquant à gracier n'a pas commis un crime de sang. Il ne semble alors pas relever de la logique de l'apartamiento. Francisca de Aguilera a ainsi été condamnée par les alcades de cour à un bannissement de la cour d'une année pour avoir vécu une «amistad ilicita» avec le capitaine d'infanterie Francisco Gómez pendant quatre ans ${ }^{84}$. Le 23 avril 1649 elle sollicite la clémence du roi sans avoir à présenter d'apartamiento puisqu'il n'y a pas de partie offensée autre que la société.

\section{La rhétorique du service de Dieu}

Le service de dieu est la formule sémantique la plus répandue dans ces exemples des pardons du Vendredi Saint, parce qu'elle semble des plus conseillées par les hommes de loi. Geronimo Fernández de Herrera Villaroel écrit ainsi «la clausula, aunque sin juramento, de que no se perdona por temor, es bien se ponga en todas las escrituras, pues con ella parece manifiesta la parte, que solo por servicio de Dios nuestro Señor, ò su conveniencia, ò otros respectos independientes de la justicia, otorga el perdon, sin que le mueva algun respeto violento, ni el que no le sera administrada justicia, pues demas de sonar bien el que las partes estèn en esta seguridad, quando contratan, facilitan el animo de los juezes a la piedad con la manifestacion que hazen, de que les consta la integridad con que procedieran si quisiesse continuar en el litigio» ${ }^{85}$. Les paroles du pardon doivent donc manifester la gratuité de l'acte et son indépendance totale envers l'objet du litige, c'est-à-dire les intérêts et les pressions divers qui en constituent la réalité sociale.

\footnotetext{
83 J. ENRIQueZ, Questiones practicas de casos morales, Córdoba, 1646, f. 48.

${ }^{84} \mathrm{AHN}$, Consejos, legajo 5576.

${ }^{85}$ G. FernándeZ de HerRera Villaroel, Practica criminal, t. II, p. 367.
} 
Certains offensés, comme la veuve de l'alguazil de cour Prudencio Ullate tombé sous les coups des frères Miguel et Pedro de la Torre en novembre 1649, rappellent qu'ils pardonnent selon leur libre et spontanée volonté ${ }^{86}$. Ils placent leur œuvre dans la volonté de Dieu, expression empruntée à la littérature religieuse.

L'intérêt de l'usage d'une telle terminologie religieuse trouve son explication dans la Vida divina y camino real del grande atajo para la perfeccion (1633) du jésuite Juan Eusebio de Nieremberg qui nous explique les différents degrés de la pureté intentionnelle du chrétien qui cherche à s'accomplir pleinement dans la volonté de Dieu.

La première marche vers la perfection commence par la dédicace de ses actes à Dieu, ce qui est le cas de tous les écrits de pardon. La deuxième étape consiste à agir par «amor de Dios», l'une des expressions favorites des notaires qui rédigent les apartamientos. Il faut ensuite manifester que l'acte est fait seulement pour l'amour de Dieu, d'où l'exclusion des intérêts financiers et familiaux dans le discours du pardon. La charité se doit d'être affirmée elle aussi comme le principal motif de l'œuvre. Le mot est parfois employé dans les pardons privés. La volonté de Dieu enfin exclut le doute et la perplexité de l'acteur. Le pardonnant ne doit pas laisser croire qu'il n'est pas convaincu par le bien fondé de son geste.

Alejo del Pozo, poursuivi par les alcades de cour depuis 1667, pour le meurtre de Nicolas López de Lara, obtient dès le 2 mars 1668 un apartamiento du père administrateur de la victime, Juan López de Lara, «pour le service de Dieu» ${ }^{87}$. Il aura fallu une longue année au père de la victime pour reconnaître que son fils avait, par ses propos insultants, provoqué Alejo de Pozo qui, l'épée sortie du fourreau, n'avait pu que se défendre et tuer «accidentellement» Nicolas López de Lara. Juan López de Lara, soucieux du service de Dieu et du devoir de vérité qu'il doit à ce dernier, fait donc écrire que l'assassin n'est pas le responsable de la mort de son fils. C'est à Nicolas López de Lara, de par les paroles offensantes proclamées, qu'incombe la responsabilité de son propre décès. Cette longue année de réflexion que s'est donné le père pour finalement pardonner correspond autant au deuil nécessaire qu'aux nécessités pratiques d'une négociation financière avec son voisin que le discours d'apartamiento censure.

Juan de Hurossa, condamné par la justice du corrégidor de Madrid pour rébellion et pour l'assassinat d'un maître d'œuvres, Francisco Pérez de Gamaro, finit par être emprisonné. Dans l'attente de l'exécution de sa peine, il

${ }^{86}$ AGS, Camara de Castilla, legajo 2575, f. 33.

${ }^{87}$ AGS, Camara de Castilla, legajo 2585.

Hispania Sacra, LX

121, enero-junio 2008, 231-266, ISSN: 0018-215-X 
réussit à bénéficier d'un apartamiento octroyé par le frère de la victime, le 28 octobre $1668^{88}$. Mais l'homicide commis dans la rue Isabel en 1667, est un meurtre collectif. Le représentant de la famille offensée fait donc bénéficier son attachement au service de Dieu à toutes les personnes responsables des faits délictueux. Le pardon du frère de Francisco Pérez de Gamaro est donc collectif, nous laissant entrevoir une rapide négociation avec le clan de Juan de Hurossa, rendue nécessaire par le risque d'un envoi aux galères du condamné. Sans cet incident, que constitue l'arrestation d'un des accusés ou des condamnés, l'octroi du pardon collectif de la partie offensée peut se faire attendre pendant de longues années. Il faut ainsi six ans à Maria de Aguilar pour pardonner aux assassins de son mari Domingo Moreno. L'apartamiento qu'elle cède, motivé par le «servicio de dios» ${ }^{89}$, n'intervient que le 9 septembre 1668 et concerne les deux personnes poursuivies par les alcades de cour, Rafael de Acevedo et Eugenio de Castro, comme toutes les autres personnes impliquées dans la mort de Domingo Moreno. Ce service de Dieu n'est accessible aux épouses qu'avec l'accord de leur mari. Le 19 août 1667, Luisa de Robles ne peut pardonner à Diego de Castro la mort du fils qu'elle eut de Blaz Diaz son premier époux, qu'avec l'autorisation de son second mari Gil de Buenas ${ }^{90}$. Diego de Castro est donc pardonné pour le meurtre de Lucas Diaz survenu rue des Postas. La femme n'acquiert sa pleine liberté de pardon qu'au prix d'un veuvage solitaire. Le remariage la plonge dans une nouvelle dépendance juridique et spirituelle.

Maria Marina, la veuve d'Antonio Camilo, laquais du duc de Terranova tué dans le quartier des Maravillas par Manuel de Velasco que les alcades de cour viennent de condamner à 10 ans de préside et 400 ducats d'amende, peut ainsi accorder son pardon le 13 novembre 1670 au «nom du service de Dieu» en toute indépendance ${ }^{91}$. Cette indépendance reste néanmoins toute relative. Dès lors que la veuve cherche à négocier avec la partie inculpée le service de Dieu qu'elle doit à son défunt mari comme curatrice des enfants mineurs que ce dernier lui a laissés, elle a besoin d'un soutien moral et juridique. C'est pourquoi le 23 mars 1668, le licencié Juan González de Lara, lieutenant du corrégidor de Madrid, fait rédiger une licence pour que «Bermeja Carnexera buida de Gaspar de la Villa, tutora y curadora de las personas y bienes de Juan y Anttonio de la Villa sus hijos en nombre de los dichos sus hijos menores haga y otorgue el apartamiento que contiene el dicho pedimiento» ${ }^{92}$.

\footnotetext{
${ }^{88}$ AGS, Camara de Castilla, legajo 2586.

${ }^{89}$ AGS, Camara de Castilla, legajo 2586.

90 AGS, Camara de Castilla, legajo 2585.

91 AGS, Camara de Castilla, legajo 2588.

92 AGS, Camara de Castilla, legajo 2585.
} 
Cette logique du «service de Dieu» peut aussi réunir toute une famille et révéler toute la complexité des négociations qui ont abouti à la rédaction d'un apartamiento. Nicolas Martinez, résident de Madrid, rencontre dans la taverne d'Ysabel Fernandez, rue de l'Espejo, des cochers du comte de Monterrey et après des insultes mutuelles, une bagarre éclate. Tous sortent leur épée et se battent ${ }^{93}$. C'est dans le contexte d'une rixe de taverne, soutenue par la boisson, que Nicolas Martinez blesse grièvement Blas de Castro et se retrouve poursuivi pour agression dès le 9 juillet 1666 par les alcades de cour. Blas de Castro décède de ses blessures en 1667. L'agression est devenue meurtre. La recherche du pardon peut donc commencer. La victime a deux fils naturels, Bartolome et Juan Díaz, qui concèdent un apartamiento à Nicolas Martinez le 5 janvier 1668, complété par un autre apartamiento motivé par le service de Dieu, celui de la sœur de la victime, Francisca López de Castro. Le pardon est familial.

\section{La DynamiQue argumentaire du SAlut DE L'ÂME}

Le service de Dieu est donc associé à d'autres arguments religieux. Le 7 août 1663, Diego Morales accorde son pardon à Andres de Lara, condamné, pour le meurtre de son fils Joseph de Morales, par le conseil de Castille à deux ans de préside en Extrémadure, deux ans de bannissement de la cour et une amende de 10000 maravédis. Il agit «por amor de Dios nuestro Señor y porque le perdone sus culpas y pecados» ${ }^{94}$. Diego de Morales ne se montre pas seulement soucieux du salut spirituel de son fils Joseph, soldat de la garde espagnole. Il renforce le caractère charitable de son geste en manifestant la miséricorde que lui inspire l'assassin de Joseph. Andres de Lara est décrit dans son apartamiento comme extrêmement pauvre et devant subvenir aux besoins d'une mère veuve et de trois jeunes sœurs donzelles. Mais cette générosité n'est pas gratuite. Elle implique que le condamné reste incarcéré dans la prison de cour jusqu'au 7 octobre 1663. Diego Morales n'efface pas la marque du péché qu'implique le crime perpétré sur la personne de son fils. Dans son Guía espiritual de 1675, Miguel de Molinos distingue deux éléments dans l'offense: d'une part le péché que porte l'auteur du crime et d'autre part la peine et la souffrance que reçoit la partie plaignante. Le premier élément, même pardonné par la victime ou celui qui la représente, demeure un acte accompli contre la volonté de Dieu. Le second élément, lui, à l'image de la passion du Christ, doit être reçu par la victime ou sa famille comme une épreuve qu'impose la volonté céleste ${ }^{95}$. L'oc-

${ }^{93}$ AGS, Camara de Castilla, legajo 2585.

${ }_{94}$ AGS, Camara de Castilla, legajo 2583.

95 «Te hace un hombre una injuria. Aquí hay dos cosas: el pecado de quien la hace y la pena de quien la padece. El pecado es contra la voluntad de Dios, y le desagrada, si bien le permite. La pena es

Hispania Sacra, LX

121, enero-junio 2008, 231-266, ISSN: 0018-215-X 
troi de l'apartamiento conclut en quelque sorte ce temps de souffrance qui est tout autant celui du deuil que de la négociation entre le père de la victime et son assassin. Le fait que bien des apartamientos indiquent la date du crime et du début des poursuites judiciaires permet de souligner la durée de cette «souffrance» et le chemin de l'acceptation de l'absence qu'elle implique. L'apartamiento conclut ce cheminement et manifeste l'acceptation de la mort des octroyants pour leur propre bien spirituel, les intégrant un peu plus dans le modèle christique de la souffrance car «se sirve este Señor de la culpa ajena para el bien de tu alma» ${ }^{96}$. Cette stratégie discursive renforce ainsi la censure de l'accord financier et de sa négociation.

Francisco Pérez et Juan López sont pardonnés le 26 octobre 1658 par Catalina de Espinoza, la veuve d'Andrès de Espinoza qu'ils ont tous deux assassiné, au nom du «servicio de dios y por que perdone el alma de su marido» ${ }^{97}$. La veuve accomplit ainsi son devoir de chrétienne et d'épouse tel que l'a défini Juan Luis Vives au XVIe siècle Celui-ci écrit en effet «que la viuda no debe pensar que su marido es del todo muerto, mas que vive con la vida del alma que es verdadera vida» et ce afin que«No tenga tal vida que el alma de su marido airada contra ella la haya de perseguir viva y muerta» ${ }^{98}$. La veuve de Francisco Garcia, Maria Angela Cortes, résidente de la cour, pardonne le 10 septembre 1666 l'acte meurtrier de Juan Pérez car l'âme de son défunt mari a déjà pardonné99. Le plus souvent, cependant, la simple attention que déclare porter la veuve à son défunt époux suffit à placer son pardon judiciaire dans le service de Dieu. Le 5 mars 1665, une autre veuve, ayant le titre de vecina de Madrid, Tomasa Gonzalez octroie son pardon à l'assassin de son mari, l'éventailliste Manuel Gómez, «porque Dios perdone el alma del dicho su marido» ${ }^{100}$. Notons qu'il aura fallu presque trois années à Tomasa Gonzalez pour considérer l'économie du salut de son époux. Pablo Ernandez a, en effet, été assassiné par Manuel Gómez en 1662.

Pour assumer son devoir de mémoire, la veuve a parfois besoin du secours d'une conscience. Maria Angela Cortes n'arrive à pardonner la mort de son mari Francisco Garcia à Juan Pérez que grâce aux conseils de «personas de conciencia»101. C'est ce qu'elle affirme dans l'apartamiento qu'elle fait rédiger en faveur de Juan Pérez le 10 septembre 1666. C'est la métaphore du poids de

conforme a su voluntad y la quiere para tu bien, y así la has de recibir como de su mano», M. de MoLINos, Guia espiritual, Madrid, reed. 1976, p. 422.

96 Idem, p. 423.

97 AGS, Camara de Castilla, legajo 2575.

98 J. L. VIVEs, Instrucción de la mujer cristiana, Madrid, trad. Castillane de Juan de Justiano, 1995, p. 363 y 364.

${ }^{99}$ AGS, Camara de Castilla, legajo 2583.

100 AGS, Camara de Castilla, legajo 2583.

101 AGS, Camara de Castilla, legajo 2583. 
la famille et du clan sur la douleur de la mère et de l'épouse. Le 9 juillet 1668 , Maria Ximenez pardonne les tailleurs Juan de Vandeslar et Francisco Calbe poursuivis par le lieutenant du corrégidor et condamnés à mort pour le meurtre de son fils Francisco de Pineda, parce que sont intervenues des personnes honorables et religieuses. La veuve Juana Zevollo utilise un procédé identique pour pardonner le meurtre de son fils et de son mari Lorenzo et Anttonio Carterron au soldat de la garde espagnole, Juan Gomez de Arrati que poursuivent les alcades de cour. Elle octroie son apartamiento du 9 mars 1671«por haverse metido de por medio personas honrradas cristianas y zelosas del serviçio de dios nuestro señor» ${ }^{102}$. L'emploi de l'influence d'un tiers pour solliciter le pardon privé est recommandé par le prédicateur Juan Enriquez qui écrit, en 1634: «puede el hombre que a ofendido a otro, pedirle perdon por tercera persona, sin ser necessario lo pida el mismo que hizo la injuria»103.

C'est plus rarement l'économie du salut propre à l'octroyant qui est mise en avant par le discours de l'apartamiento. Le père d'Andres Antonio de Espinosa, un laquais du marquis de Cadereyta assassiné vers 2 heures du matin sur la Plaza mayor le 16 juillet 1634, fait appel, pour justifier le pardon qu'il donne à l'accusé Baltasar Pérez le 13 août 1636, à l'autorité de Dieu, de la Sainte Vierge et du Saint Esprit «deseando poner mi anima en carrera de salvazion», «servicio de Dios el descargo de mi anima y conciencia»104. Que l'auteur de cet apartamiento soit un homme, probablement assez âgé, explique en partie une telle démarche.

Celle-ci n'est en effet accessible aux femmes qu'au prix d'une grande prudence oratoire. Le 15 septembre 1666, Catalina López pardonne Esteban de Castro pour la mort de son frère Francisco Barrera « por hacer servicio a dios y descargar su conciençia y hacer buena obra al dicho esteban de castro» ${ }^{105}$. La veuve d'Antonio de Castro ne peut pardonner la mort de son mari à son meurtrier poursuivi par la justice du corrégidor de Madrid depuis 1666, Alonso Guerrero, qu'en se référant au service de Dieu et au soulagement de sa propre conscience afin que l'âme de son défunt mari obtienne plus facilement la grâce du ciel. Maria Garcia a du mal à accorder son pardon. Elle fait écrire dans le texte de l'apartamiento de 1668 «que lo echo no se puede remediar» ${ }^{106}$, manifestant par là un dilemme intérieur. Femme pieuse et veuve consciente de son devoir, elle soulage son âme en reliant son pardon à la quête du salut de son défunt époux. Les problèmes de conscience de Maria Garcia justifient ainsi la longue attente du pardon (presque deux ans) et nous lais-

\footnotetext{
102 AGS, Camara de Castilla, legajo 2588.

103 J. EnRIQUeZ, Compendio de casos morales, Sevilla, Francisco de Lyra, 1634, f. 60.

104 AGS, Camara de Castilla, legajo 2567, f. 26.

105 AGS, Camara de Castilla, legajo 2583.

106 AGS, Camara de Castilla, legajo 2585.
}

Hispania Sacra, LX

121, enero-junio 2008, 231-266, ISSN: 0018-215-X 
sent croire que l'accord financier que censure le discours d'apartamiento fut difficile à négocier. Plus originales encore semblent les paroles de la veuve Maria González de Azevedo qui, le 21 février 1669, octroie son pardon à Juan Antoliner y Vega condamné par les alcades de cour pour le meurtre de son époux Juan de Santillana à 8 ans de préside et 50 ducats d'amende. Maria González de Azevedo fait écrire «otorgue apartamiento a fabor del susso dicho y por que dios nuestro Señor perdone el alma del dicho Juan de Santillana su marido y a ella quando destte mundo baya y por ser util y provechoso el otorgar dicho apartamiento por las raçones dichas moveda del fuero de su conciencia»107.

\section{LE MYSTÈRE DE LA GRÂCE ROYALE}

L'apartamiento constitue le sommet hiérarchique des stratégies du pardon. Ce type de discours offre aux justiciables les plus grandes virtualités juridiques, morales et informatives. Tous les autres gestes d'apaisement, toutes les autres manifestations du pardon semblent se poser par rapport à lui ou conduire leurs auteurs vers lui. C'est que cet acte discursif détient la propriété de faire croire à son auteur qu'il restera le maître de sa mort, que sa mort n'appartient qu'à lui. Les apartamientos rencontrés dans les archives des hôpitaux marquent en effet une volonté des blessés de maîtriser le devenir de l'unité familiale après leur décès, et laissent émerger une série de réponses destinées à prévenir les stratégies possibles de leur parentèle. L'apartamiento devient dans leur bouche l'héritage fondateur d'une nouvelle histoire familiale. C'est la voix des femmes battues qui montre le mieux cette situation.

La littérature des apartamientos démontre l'importance du discours religieux pour pacifier les rapports internes de la société madrilène et pour faire de la cour un modèle judiciaire de gouvernance à proposer aux autres vassaux des Habsbourg. Elle manifeste l'intégration d'une pratique de médiation religieuse dans le processus de judiciarisation de la société d'Ancien Régime.

L'absence du pardon de la partie offensée peut être considérée comme dramatique pour les condamnés qui sollicitent la grâce du roi. La littérature des Practicas judiciaires nous conduit à le penser. Certains solliciteurs intègrent cette dramatisation dans leur dialogue avec la Camara de Castilla.

Mais ne faut-il pas aussi nous interroger sur la portée réelle de l'apartamiento dans l'obtention d'un pardon royal du Vendredi Saint? En réalité, l'acte d'apartamiento n'est qu'une des nombreuses tactiques du solliciteur. Par exem-

${ }^{107}$ AGS, Camara de Castilla, legajo 2586. 
ple, en 1666, le charpentier Juan Martínez, poursuivi depuis le premier janvier 1663 , par les alcades de cour pour avoir participé à la mort du soldat de la Vieille Garde du roi, Prudençio Martinez de Zarate, fait présenter à la régente le pardon de la veuve de la victime Maria Gonzalez, aussi bien attachée au service de Dieu qu'au salut de l'âme de son défunt époux. Mais, il accompagne le texte de cet apartamiento du 10 juin 1665, d'une lettre personnelle dans laquelle il fait écrire qu'il est pauvre et doit subvenir aux besoins d'une mère, d'une épouse et de 4 enfants. Considérant tous ces éléments, il demande à la reine mère d'inscrire la grâce royale dans la générosité chrétienne de la veuve de sa victime, Maria González. Il précise que sa grâce serait pour la monarchie catholique une œuvre charitable et répondrait d'autant mieux au service de Dieu. Dès le 29 septembre 1666, la reine mère répond à son propos au président de Castille: «La camara veera el memorial incluso que se me ha dado de parte de Juan Martinez official de carpinteria preso en la carzel real de esta corte y con atencion a las causas de piedad que alega, se me consultara lo que ofreciere y pareciere en el perdon que soliçita»108. La documentation utilisée ne nous permet cependant pas de conclure une éventuelle réussite des démarches de Juan Martinez.

Dans d'autres cas, la grâce royale n'aboutit pas à la libération du suppliant de toute peine. Le 8 mai 1647 le corrégidor de Madrid décide, après enquête, de faire arrêter Antonio de la Cosa pour le meurtre de sa servante Catalina Duranga ${ }^{109}$. Ce dernier réussit à s'enfuir et négocie avec le mari de la victime, le savetier Antonio Hernández, un apartamiento signé dès le 8 décembre 1647. Le conseil de la Chambre de Castille examine sa requête de grâce dès le 3 février 1648 alors que la procédure pénale suit son cours. L'inculpé cherche à être gracié avant d'être condamné par le corrégidor. Les annotations en marge de sa requête nous indiquent que la clémence royale du Vendredi Saint s'est traduite par sa condamnation à 4 ans de service militaire. Philippe IV s'est substitué au juge, répondant à son vassal par la rémission d'une peine non prononcée, tout en considérant les intérêts politiques de la monarchie qui a bien du mal à recruter de nouvelles armées pour combattre les rebelles du Portugal et de Catalogne.

Pedro Provanza est l'un des rares Madrilènes dont la documentation atteste de la réussite du recours en grâce. Condamné à mort par les alcades de cour pour le meurtre d'une esclave perpétré en 1643 et pour fuite, il voit finalement sa peine commuée en appel par ces mêmes juges en 8 ans de galères ${ }^{110}$. La cédule royale du 21 avril 1655 prononce sa grâce. Il obtient de Philippe IV une rémission de peine. Les 8 ans de service dans les galères sont oubliés au profit d'un bannissement de la cour et des 5 lieues alentours.

\footnotetext{
108 AGS, Camara de Castilla, legajo 2584.

109 AGS, Camara de Castilla, legajo 2571.

110 AGS, Camara de Castilla, legajo 2577.
}

Hispania Sacra, LX

121, enero-junio 2008, 231-266, ISSN: 0018-215-X 


\section{CONCLUSION}

La culture de l'apartamiento interroge la place du religieux dans les relations entre l'espace privé et l'espace public d'une grande ville, Madrid. Relevant d'un discours religieux, cette culture s'ancre dans la tradition théologico-juridique 111 , lui emprunte une partie de ses catégories (les obligations religieuses du cadre testamentaire, le statut de la femme et de la veuve, l'affirmation de la domination masculine) et de sa rhétorique (le service de Dieu, le salut de l'âme) pour exorciser la cour de la «universidad de vicios» qui la rongerait ${ }^{112}$. Elle intègre les valeurs et les discours de la morale chrétienne, impliquant pour ses acteurs, une posture d'humilité, de compassion et de charité.

Le rôle de l'apartamiento dans les litiges judiciaires de la société madrilène nous montre comment une justice d'Ancien Régime se détermine aussi bien par rapport à des normes religieuses que des normes strictement juridiques ${ }^{113}$. Dépositaires de la conscience du monarque, les tribunaux de la monarchie catholique dirigent un système autant religieux que juridique.

C'est donc cette double nature qui permet aux acteurs de l'apartamiento de le revendiquer comme une politique de justice prescriptive. Les auteurs du pardon privé réclament la fin des poursuites ou des condamnations prononcées à l'encontre du délinquant. Ils dotent les mots de la rhétorique du «service de Dieu» d'une efficacité symbolique pour légitimer leur droit à pardonner et obliger implicitement les magistrats à l'exécuter. La dialectique entre le caractère sacré du pardon accordé, la renonciation de la partie offensée à sa plainte et à ses droits sur lesquels le texte de l'apartamiento insiste plus encore, dès lors que l'auteur est une femme, puis l'obligation morale (nous avons vu qu'elle n'avait aucune valeur juridique) de supprimer les poursuites et éventuellement d'annuler la sentence prononcée, constitue un véritable discours rituel ${ }^{14}$. En revendiquant le caractère performatif de leur généreux énoncé, ceux qui pardonnent construisent ainsi l'apartamiento autour d'une sorte de langage autorisé, dont ils espèrent extraire les conditions sociales de son succès. Le langage à l'œuvre dans le discours d'apartamiento sert à décrire autant qu'à prescrire les conditions de possibilité de la pacification entre les familles madrilènes en litige. Sa

111 Antonio Manuel Hespanha, «La senda amorosa del derecho. Amor y iustitia en el discurso jurídico moderno», C. Petit (ed.), Pasiones del jurista. Amor, memoria, melancolía, imaginación, Madrid, 1997, p. 32-33.

112 F. Bermúdez de Pedraza, Hospital real de la corte, Granada, 1644, f.3.

113 Bartolomé Clavero, «La monarquía, el derecho y la justicia», E. Martínez Ruiz y M. de PAZZIS PI (coord.), Instituciones de la España Moderna. Las jurisdicciones, Madrid, 1996, pp 37-38.

114 P. Bourdieu, Ce que parler veut dire. L'économie des échanges linguistiques, Paris, 1982, p. 103. 
force de représentation, qui réside dans la capacité des auteurs à reformuler le crime et la définition du criminel, ne peut pas fonctionner sans censures.

La volonté de vérité des auteurs, qui doit s'inscrire dans le discours du pardon privé, a un support institutionnel dans la mesure où les greffiers qui le rédigent se réfèrent à des modèles issus de l'Institution judiciaire (ce dont témoignent les livres de pratique judiciaire étudiés) et de l'Institution religieuse (l'idéologie de justice des théologiens), tous deux liés à la culture de la contre-réforme catholique. Le propos s'organise autour de la question de l'aveu, que la confession auriculaire revendiquée et strictement codifiée par l'Église catholique après le concile de Trente (1545-1565) promeut ${ }^{115}$. La Nueva Recopilación (1567-1640) et la nouvelle littérature des livres de pratique judiciaire -après 1566- permettent à leurs auteurs de mettre en avant des analogies plus explicites qu'auparavant entre l'aveu judiciaire du délit et l'aveu du péché en confession. La reconnaissance du délit qu'implique la signature d'un apartamiento est un appel à la clémence du roi et de ses tribunaux, comme la contrition est dans la confession auriculaire un appel à la miséricorde de Dieu. Elle ouvre la voie à la réconciliation du délinquant avec les parties plaignantes (l'offense privée) et l'ensemble de la communauté (l'offense publique) comme la confession à un prêtre est une demande de réconciliation avec l'Église. La réparation des maux causés à la partie offensée n'apparaît explicitement que lorsqu'elle est assimilée à des œuvres de justice et de charité, analogies de la pénitence spirituelle du pécheur lors du moment de la satisfaction dans le système de la confession auriculaire.

L'accord financier représente souvent dans ce système discursif le principal objet tabou des procédures d'exclusion qui permettent aux auteurs de croire qu'ils restent les maîtres de l'apartamiento. Nous avons vu, par exemple, qu'un agonisant pouvait, dans son testament, pardonner à son assassin, mais devait aussi veiller à ce que son pardon, dont l'efficacité se limite à l'économie de son seul salut, puisse ne pas gêner une nouvelle plainte déposée par sa famille contre l'agresseur, tout en légitimant par avance la négociation d'un apartamiento de sa veuve ou d'un parent, capable d'apporter à sa famille une réparation financière pour la perte de revenu qu'implique sa mort prochaine. Les auteurs de l'apartamiento ont toujours à cœur de maîtriser les pouvoirs d'un acte qui pourraient leur échapper. Seule la libération de l'accusé ou du condamné garantit réellement le paiement total de la somme réparatrice par celui-ci ou sa famille. Ils savent aussi que désormais tout dépend des magistrats et du roi. Une fois écrit et signé l'apartamiento n'appartient plus qu'à son bénéficiaire qui très vite le dépose dans le mystère de la grâce royale.

115 P. VAladieR, «Pratique catholique de la confession auriculaire: enjeux et problèmes», R. DULONG (dir.), L'aveu. Histoire, sociologie, philosophie, Paris, PUF, 2001, p. 247.

Hispania Sacra, LX

121, enero-junio 2008, 231-266, ISSN: 0018-215-X 
C'est au moment de cette dépossession, dont le conseil de la Chambre de Castille organise le rite, que la pratique de l'apartamiento change d'échelle. D'abord cantonnée au dialogue entre des familles en litige, entre des justiciables et des tribunaux, elle acquiert désormais une portée politique pour entrer dans l'économie de la libéralité du roi catholique, c'est-à-dire des dons royaux. En 1690, le traité du licencié Juan López de Cuellar y Vega nous rappelle que cet exercice du don répond à des règles. L'apartamiento est la principale attitude capable de susciter le don du roi, qui par ailleurs, se veut gratuit et explique l'absence de la moindre justification des grâces pénales accordées, aussi bien dans les dossiers de demande de pardon du Vendredi Saint que dans les traces des registres conservés. Le pardon de la partie offensée est présenté comme un don de la victime dont la gratuité, renforcée par l'argumentaire religieux du service de Dieu et de l'économie du salut comme par la censure de l'accord financier s'il ne profite pas directement à autrui (la pauvreté des enfants, de l'épouse, des parents), implique une rétribution supérieure: la clémence du roi. La grâce pénale du monarque est supérieure à deux titres. D'abord, elle garantit une «spirale de rapports sociaux fondés sur la bienfaisance et la gratitude réciproques»116, assurant la fidélité des vassaux. Nombreux sont les écrivains politiques du XVIIe siècle à croire remarquer cela ${ }^{117}$. Ensuite, elle est supérieure car elle souligne la puissance du donneur -le roi catholique- sur ses sujets et réaffirme la gratuité de la clémence du Prince. Le roi pardonne au délinquant, ce qui n'apporte aucun bienfait direct à l'auteur de l'apartamiento, à la partie offensée, mais réussit ainsi à placer les deux personnages dans une stratégie commune, une même imitation de la charité du Christ.

L'identité religieuse du discours de l'apartamiento s'inscrit donc dans la promotion de la fonction monarchique et dans la construction d'un imaginaire collectif capable de le soutenir ${ }^{118}$. Le roi de grâce ne contredit pas le roi de justice. La force du châtiment n'acquiert son éclatante exemplarité que par le mystère du pardon royal espéré qui en limite la portée. La contradiction entre ces deux piliers de la fonction monarchique est tout au plus symbolique, puisque plus de 70\% des demandes de pardon du Vendredi Saint relèvent d'accusés ou de condamnés en fuite c'est-à-dire de délinquants que les tribunaux n'ont pas les moyens effectifs de punir ${ }^{119}$. Le second doit permettre de tempérer la

116 António Manuel HespanhA, «Les autres raisons de la politique. L'économie de la grâce», J. F. Schaub (coord.), Recherche sur l'histoire de l'État dans le monde ibérique (15e-20e siècle), Paris, 1993, p. 70.

117 J. A. Maravall, La philosophie politique espagnole au XVIIe siècle dans ses rapports avec l'esprit de la contre-réforme, Paris, 1955 (1946), pp 187-221.

118 Maria Paz Alonso et Antonio Manuel Hespanha, «Les peines dans les pays ibériques (XVIIeXIXe siècles)», Recueils de la société Jean Bodin pour l'histoire comparative des institutions. La peine, Louvain, 1989, LVII, 3e partie, 195-225.

119 José Luis de Las Heras SANTOS, «Indultos concedidos por la Camara de Castilla en tiempos de los Austrias», Studia Historica, I, n³, 1983, 115-141. 
dureté croissante de la loi pénale. Il participe de l'arbitrium et joue en ce sens un rôle de régulation. La politique de l'apartamiento relève en effet de l'arbitrium super bono et pacifico statu civitatis parce qu'elle a pour objectif de maintenir la paix entre les familles qui composent la cité et par conséquent l'harmonie de celle-ci ${ }^{120}$.

Mais le plus important n'est pas là. En intégrant la pratique de l'apartamiento dans l'économie de la grâce royale les juristes castillans tentent de soumettre l'arbitraire des juges à l'arbitraire du roi. Les auteurs de l'apartamiento ne se contentent plus d'en appeler à l'arbitraire des juges, ils implorent directement le roi et le supplient de gracier le criminel. Le roi catholique s'affirme comme la source unique de toute juridiction en matière temporelle. La littérature des livres de pratique judiciaire conforte depuis 1567 cette revendication. Toutes les juridictions sont désormais considérées comme déléguées par le monarque qui, en droit, peut les enlever à ses mandataires au profit d'autres magistrats. Le pouvoir de juridiction suprême relève du monopole royal et l'arbitraire du roi, désormais supérieur à tous les autres, peut corriger les injustices pénales de ses juges. L'arbitrium suprême du souverain, qui se manifeste dans la grâce royale, ne sert plus seulement à tempérer la dureté des peines prévues par la loi royale, mais à limiter l'indétermination de celles-ci par l'arbitraire du juge. Tous les récits d'apartamiento semblent reconnaître l'injustice que produit la sentence du juge. Les pardons royaux individuels, comme ceux du Vendredi Saint, relèvent donc d'une politique plus ample de dévalorisation de l'arbitraire des juges royaux qui doit beaucoup à la théologie juridico-morale ${ }^{121}$.

Cependant, la grâce du roi que nous avons étudiée ne répond pas seulement aux impératifs de gouvernement précédemment explicités. Nous ne devons pas oublier que les justiciables dont nous avons eu à suivre le parcours dans l'économie de la clémence royale appartiennent à une ville de cour dont les Habsbourg ont décidé de faire la vitrine de leur monarchie, la capitale de la police chrétienne. Depuis 1606, l'exercice de la clémence royale est là aussi pour construire un lien privilégié entre le monarque et sa bonne ville de Madrid. La dialectique du pardon privé et du pardon royal doit résoudre les conflits internes aux familles madrilènes et à la société urbaine. Elle prétend rétablir l'ordre symbolique de la ville de cour parce qu'elle implique le renoncement à la vio-

\footnotetext{
120 Massimo Meccarelli, Arbitrium. Un aspetto sistematico degli guiridici in età di diritto comune, Milano, 1998, pp 175-183.

${ }^{121}$ Citons pour exemple cette exclamation: «O quanto lugares, y Reynos han sido perdidos, no tanto por los daños que los malos en ellos cometieron, quanto por las desasoradas justicias que los ministros executaron, porque pensando con su rigor corregir los daños passados, despertaron escandalos nunca oidos», M. de Zubiaur, Peso y fiel contraste de la vida y de la muerte. Avisos y desengaños, exemplares, morales y politicos, Madrid, 1650, f. 53.
}

Hispania Sacra, LX

121, enero-junio 2008, 231-266, ISSN: 0018-215-X 
lence ${ }^{122}$. Avec l'apartamiento, la partie offensée renonce à la vengeance. Avec le pardon du Vendredi Saint, le roi catholique renonce aux peines corporelles, parfois au profit de peines plus politiques (le service des galères pour suppléer au manque de rameurs dans la flotte méditerranéenne). La part des Madrilènes dans les demandes de Vendredi Saint ne cesse de s'accroître au cours du XVIIe siècle. La concentration des tribunaux suprêmes et d'une nombreuse population de letrados dans une ville de cour permet, plus qu'ailleurs, de rencontrer rapidement un démarcheur pour défendre les intérêts du suppliant ${ }^{123}$. Des couches sociales aisées plus nombreuses ont les moyens financiers d'entreprendre de telles démarches et bénéficient des réseaux de clientèle plus efficaces. Ainsi, l'apartamiento, dont la pratique notariale n'est pas le monopole des Madrilènes, s'intègre d'autant mieux dans le système de la grâce royale. Plus qu'un facteur de régulation strictement urbain, il offre une plus grande prégnance à l'arbitrage souverain sur la capitale. Néanmoins, les pardons du Vendredi Saint ne représentent qu'une partie de l'arsenal des grâces royales.

S'intégrer à ces stratégies suppose que l'apartamiento réponde à un certain art de la narration. Le récit de pardon est déterminé aussi bien par les aspects fonctionnels du discours que par ses structures formelles. Nous en avons relevé quelques-unes dans notre analyse du pardon de la partie offensée des Madrilènes. Mais les fonctions narratives de l'apartamiento sont encore plus riches d'enseignement pour l'historien, si nous considérons ce que Carlo Ginzburg a pu qualifier de «fêlures», qui introduisent une distance entre l'auteur et son texte ${ }^{124}$. Ces failles du discours de l'apartamiento nous permettent de déceler de véritables ambiguités entre la souffrance de l'auteur et la «générosité» affichée de son propos. Nous avons pu relever à plusieurs reprises que la partie offensée semble parfois incapable de censurer sa douleur. Telle ou telle veuve exige de ne plus rencontrer l'assassin de son mari et conditionne son pardon à la promesse que l'accusé s'exilera de la cour. Dans d'autres cas, on demande que l'inculpé reste quelques mois de plus en prison, nous laissant comprendre qu'il s'agit de respecter le deuil et la souffrance de la famille. L'ambiguïté de l'apartamiento, dont témoignent les fêlures du texte est là. La victime, en octroyant son pardon à l'agresseur, lui fait le sacrifice de sa douleur, de sa souffrance physique et surtout psychologique. Quand les censures du discours sont insuffisantes à masquer cette souffrance, des fêlures s'ouvrent et nous distribuent des indices sur l'affection des auteurs et sur le poids social des réseaux qui, au bout de longs mois de négociation, ont permis de faire triompher la raison, l'intérêt de la collectivité.

122 Sur les rapports entre ordre et violence voir Wolfgang SOFSKY, Traité de la violence, Paris, 1998, p. 17.

${ }^{123}$ E. Balancy, p. 461.

${ }^{124}$ Carlo GinZBURG, Rapports de force. Histoire, rhétorique, preuve, Paris, 2003, pp 80-81. 
Plus qu'une simple manifestation de la concurrence des pardons, la pratique de l'apartamiento des Madrilènes du XVIIe siècle nous a permit d'esquisser une «anthropologie de la régulation des conflits» qu'il s'agit désormais de confronter aux techniques de gouvernement des Habsbourg dans leurs autres États ${ }^{125}$. Elle s'inscrit ainsi dans une politique de la grâce comme instrument d'obéissance et de sujétion, que développe l'ensemble des monarchies européennes en fonction de leurs propres législations. Elle implique donc l'essor de la justice souveraine, surtout après 1550 .

125 Xavier Rousseaux et Élise Mertens De WiLmars, «Concurrence du pardon et politiques de la répression dans les Pays Bas espagnols au 16e siècle. Autour de l'affaire Charlet, 1541», J. HOAREAUDodinau, X. Rousseaux et P. TeXIER (textes réunis par), Le pardon, Louvain, Cahiers de l'Institut d'Anthropologie Juridique n³, 1999, 385-417.

Hispania Sacra, LX

121, enero-junio 2008, 231-266, ISSN: 0018-215-X 